\title{
A calcium channel mutant mouse model of hypokalemic periodic paralysis
}

\author{
Fenfen Wu, ${ }^{1}$ Wentao Mi, ${ }^{1}$ Erick O. Hernández-Ochoa, ${ }^{2}$ Dennis K. Burns, ${ }^{3}$ Yu Fu, ${ }^{1,4}$ Hillery F. Gray, ${ }^{1}$ \\ Arie F. Struyk, ${ }^{5}$ Martin F. Schneider, ${ }^{2}$ and Stephen C. Cannon ${ }^{1,4}$
}

\begin{abstract}
1Department of Neurology and Neurotherapeutics, University of Texas Southwestern Medical Center, Dallas, Texas, USA.
2Department of Biochemistry and Molecular Biology, University of Maryland School of Medicine, Baltimore, Maryland, USA. ${ }^{3}$ Department of Neuropathology and ${ }^{4}$ Program in Neuroscience, University of Texas Southwestern Medical Center, Dallas, Texas, USA. 5 Merck Research Laboratories, North Wales, Pennsylvania, USA.
\end{abstract}

\begin{abstract}
Hypokalemic periodic paralysis (HypoPP) is a familial skeletal muscle disorder that presents with recurrent episodes of severe weakness lasting hours to days associated with reduced serum potassium $\left(\mathrm{K}^{+}\right)$. HypoPP is genetically heterogeneous, with missense mutations of a calcium channel ( $\left.\mathrm{Ca}_{v} 1.1\right)$ or a sodium channel ( $\mathrm{Na}_{\mathrm{V}} 1.4$ ) accounting for $60 \%$ and $20 \%$ of cases, respectively. The mechanistic link between Ca 1.1 mutations and the ictal loss of muscle excitability during an attack of weakness in HypoPP is unknown. To address this question, we developed a mouse model for HypoPP with a targeted $\mathrm{Ca}_{v} 1.1 \mathrm{R} 528 \mathrm{H}$ mutation. The $\mathrm{Ca}_{\mathrm{v}} 1.1 \mathrm{R} 528 \mathrm{H}$ mice had a HypoPP phenotype for which low $\mathrm{K}^{+}$challenge produced a paradoxical depolarization of the resting potential, loss of muscle excitability, and weakness. A vacuolar myopathy with dilated transverse tubules and disruption of the triad junctions impaired $\mathrm{Ca}^{2+}$ release and likely contributed to the mild permanent weakness. Fibers from the $\mathrm{Ca}_{v} 1.1 \mathrm{R} 528 \mathrm{H}$ mouse had a small anomalous inward current at the resting potential, similar to our observations in the $\mathrm{Na}_{v} 1.4 \mathrm{R} 669 \mathrm{H}$ HypoPP mouse model. This "gating pore current" may be a common mechanism for paradoxical depolarization and susceptibility to HypoPP arising from missense mutations in the 44 voltage sensor of either calcium or sodium channels.
\end{abstract}

\section{Introduction}

Hypokalemic periodic paralysis (HypoPP) is an inherited disorder of skeletal muscle in which recurrent attacks of weakness occur in association with low serum $\mathrm{K}^{+}(<2.8 \mathrm{mM})(1,2)$. During an acute attack, fibers in affected muscles are electrically inexcitable because a depolarized shift in the resting potential $\left(V_{\text {rest }}\right)$ causes sodium channels to be chronically inactivated. This depolarization of $V_{\text {rest }}$ from $-90 \mathrm{mV}$ to $-60 \mathrm{mV}$ paradoxically occurs in the setting of low extracellular $\mathrm{K}^{+}(3)$, which is normally associated with hyperpolarization of excitable cells. The ictal hypokalemia is caused by a shift of $\mathrm{K}^{+}$from the extracellular space into the myoplasm, and episodes of weakness and may be triggered by carbohydrate ingestion, rest after exercise, or stress. The inheritance pattern is autosomal dominant, with a reduced prevalence of acute attacks in females (4), whereas both males and females often develop lateonset permanent proximal weakness with vacuolar myopathy (5).

The molecular defect in HypoPP is heterogeneous (6): $60 \%$ of families with HypoPP have missense mutations in CACNA1S encoding the L-type calcium channel Cav1.1 $(7,8)$, another $20 \%$ have missense mutations in SCN4A encoding the voltage-gated sodium channel $\mathrm{Na}_{\mathrm{v}} 1.4$ (9), and the remainder have undetermined mutations. Curiously, all 8 mutations in Nav1.4 and 6 of 7 mutations in $\mathrm{Ca}_{v} 1.1$ (Figure 1A) occur at arginine residues in the fourth transmembrane segment (S4) voltage-sensor domains $(10,11)$. Functional expression studies in heterologous systems initially focused on voltage-dependent gating of HypoPP mutant channels, and while modest disruption of $\mathrm{Na}_{v} 1.4$ inactivation $(12,13)$ and slowed Cav1.1 activation with reduced current density were observed $(14,15)$, none of these changes readily explained the sus-

Conflict of interest: The authors have declared that no conflict of interest exists. Citation for this article: J Clin Invest. 2012;122(12):4580-4591. doi:10.1172/JCI66091. ceptibility to paradoxical depolarization of $V_{\text {rest }}$ in low $\mathrm{K}^{+}$that is the pathological hallmark of HypoPP fibers.

New insights on the pathomechanism for HypoPP were derived from recent work on the structural basis for voltage-dependent channel gating $(16,17)$. In response to changes in membrane potential, the S4 voltage sensor translocates through a crevasse or "gating pore" in the channel protein. Missense mutations of the S4 segment may produce a leak or gating pore current that allows ions to pass through this aberrant conduction pathway $(18,19)$. In frog oocytes, where high levels of membrane expression for $\mathrm{Na}_{v} 1.4$ can be achieved, small gating pore currents have been detected for all 6 Nav1.4 HypoPP mutations studied to date $(16,17,20,21)$. We also detected a gating pore current in voltage-clamped muscle fibers from a mouse model of HypoPP with a knock-in $\mathrm{Na}_{v} 1.4$ R669H mutation (22). The leakage current through the gating pore in HypoPP-Nav1.4 channels is active at $V_{\text {rest }}$ and produces a susceptibility to paradoxical depolarization of $V_{\text {rest }}$ for $\mathrm{K}^{+}$concentrations less than $3 \mathrm{mM}$ via a K-dependent balance of current through the inward-rectifying $\mathrm{K}^{+}$channel $\left(\mathrm{K}_{\mathrm{IR}}\right)(11,23,24)$. The homologous location of $\mathrm{S} 4$ missense mutations in $\mathrm{Ca}_{\mathrm{V}} 1.1$ associated with HypoPP has led to the hypothesis that the anomalous gating pore current is a common molecular mechanism whereby mutations of either Nav1.4 or Cav1.1 may cause HypoPP. Because $\mathrm{Ca}_{\mathrm{V}} 1.1$ does not express well in heterologous systems, it has not previously been possible to experimentally test whether HypoPP$\mathrm{Ca}_{v} 1.1$ is indeed caused by a gating pore leakage current.

To create a system for which the molecular mechanism of Cav 1.1 HypoPP could be addressed experimentally, we developed a mouse model using a targeted missense substitution, CaV1.1 R528H, of arginine to histidine at the outermost charged residue of the $\mathrm{S} 4$ voltage sensor in domain II. The mice have a robust HypoPP phenotype with muscle weakness and paradoxical depolarization of 

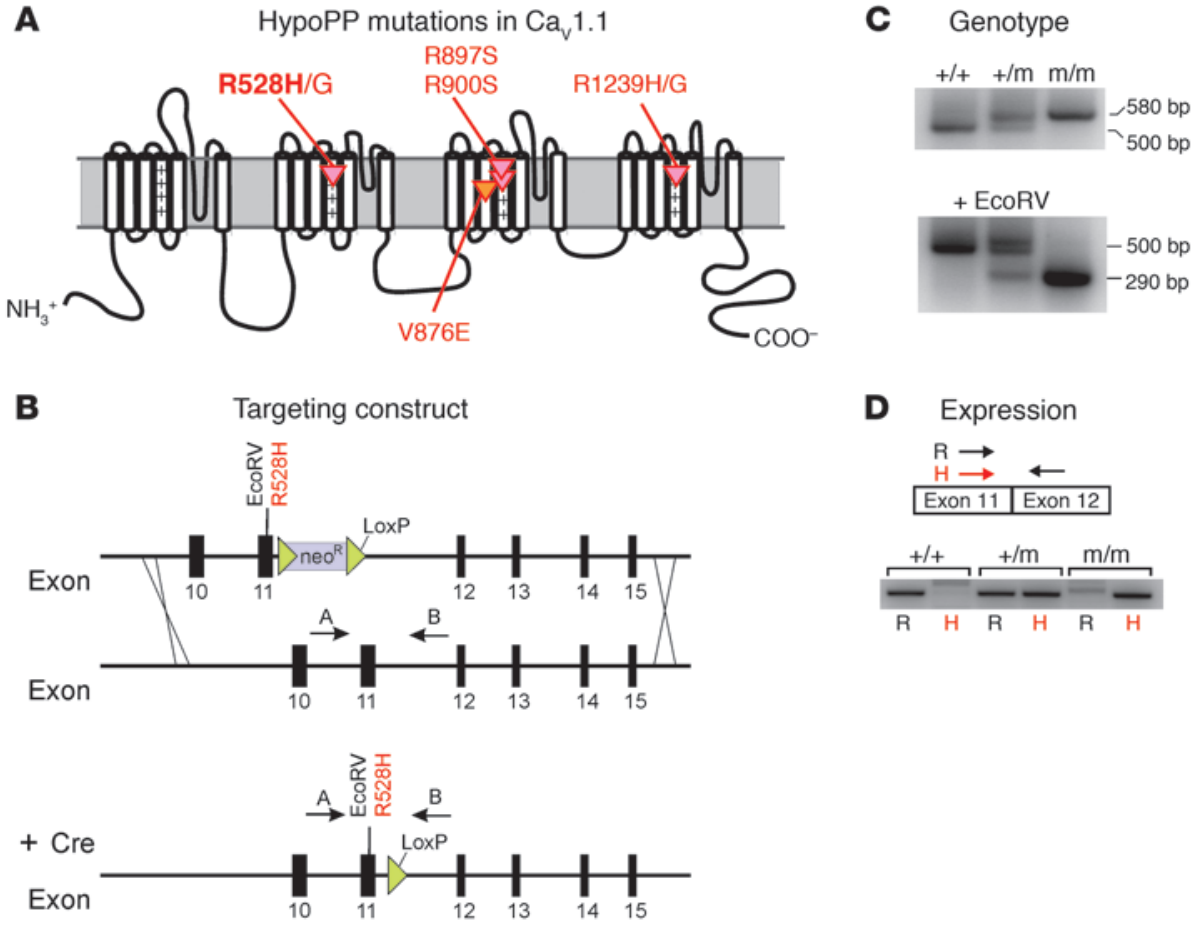

Figure 1

Construction and genetic analysis of the Cav1.1 R528H mouse. (A) A schematic diagram of the $\alpha_{15}$ subunit for the Cav1.1 calcium channel shows the locations for all known HypoPP mutations. All are missense substitutions, with 6 of 7 being at arginines in voltage-sensor domains (red triangles) and $1 \mathrm{in}$ an adjacent transmembrane segment (orange triangle). The $\mathrm{R} 528 \mathrm{H}$ mutation is in the outermost arginine of the S4 segment in domain II. (B) The targeting construct for homologous recombination in mouse CACN1S contained the R528H mutation and a silent EcoRV site. Primers $A$ and $B$ were used for genotyping and are complementary to intronic sequence flanking exon 11. (C) PCR amplification from genomic DNA shows a 500-bp WT amplimer and a 580-bp mutant amplimer with a Cre-deleted NeoR gene and retention of a short intronic LoxP site. Correct insertion of the R528H mutation was confirmed by sequencing. EcoRV digest cut the entire 580 -bp product from $\mathrm{R} 528 \mathrm{H}^{\mathrm{m} / \mathrm{m}}$ mice but did not cut the 500-bp amplimer from WT or R528H+/m mice. (D) Expression of WT $(+/+)$ and R528H RNA was determined with RT-PCR using allele-specific forward primers and a reverse primer from the next exon. The agarose gel shows allele specificity with a 128-bp product with only the R primer in WT and only the $\mathrm{H}$ primer in $\mathrm{R} 528 \mathrm{H}^{\mathrm{m} / \mathrm{m}}$.

$V_{\text {rest }}$ in response to low $\mathrm{K}^{+}$challenge. This knock-in Cav $1.1 \mathrm{R} 528 \mathrm{H}$ mouse is the only model for HypoPP caused by a mutation of CACNA1S, and the R528H mutation is the most common cause of familial HypoPP in man. Voltage clamp studies of isolated fibers revealed an anomalous inward current at hyperpolarized potentials and thereby supported the hypothesis that susceptibility to HypoPP is caused by gating pore currents conducted by $\mathrm{Na}_{v} 1.4$ or $\mathrm{Ca}_{v} 1.1$ channels in which missense mutations occur at arginine residues in the $\mathrm{S} 4$ voltage sensors.

\section{Results}

Generation of $\mathrm{Ca}_{V} 1.1$ R528H mice. The Cav $1.1 \mathrm{R} 528 \mathrm{H}$ mutation associated with HypoPP in humans was introduced into the mouse ortholog (mCaV1.1 R528H) by homologous recombination in exon 11 of CACNA1S (Figure 1). Mouse and human Cav1.1 share $92 \%$ identity at the amino acid level, with most differences residing in the carboxyl terminus. The R528H mutation is within a voltage-sensor domain of the channel at $\mathrm{S} 4$ in the second homologous repeat, DIIS4 (Figure 1A), which is identical for 21 delian frequency $\left(\mathrm{R} 528 \mathrm{H}^{\mathrm{m} / \mathrm{m}}, 26 / 106\right)$.

of 22 residues with a conserved leucine (human) to isoleucine (murine) substitution at L535. The targeting vector (Figure $1 \mathrm{~B}$ ) was constructed in pGKNeoLoxPDt2 and contained the R528H missense mutation, a transcriptionally silent EcoRV site to aid in genotyping by restriction digest, and $9.2 \mathrm{kB}$ of flanking genomic sequence. Screening for recombination in 129/ SV ES cells and blastocyst injection were performed at the University of Texas Southwestern Transgenic Core Facility. Founder mice had a high degree of chimerism, and germline transmission with correct integration of the mutant allele was confirmed by sequencing genomic DNA. The NeoR gene from the intron downstream of exon 11 was excised by crossing with a strain expressing Cre recombinase. Genotyping by PCR amplification of exon 11 from tail-snip DNA showed a 500-bp WT amplimer and a 580-bp product from the mutant allele that retained a LoxP site and contained a unique EcoRV restriction site (Figure 1C). Throughout the text we refer to the heterozygous $C A C N A 1 S^{+/ R 528 H}$ and homozygous CACNA1S $S^{\mathrm{R} 228 \mathrm{H} / \mathrm{R} 528 \mathrm{H}}$ mutant mice as $\mathrm{R} 528 \mathrm{H}^{+/ m}$ and $\mathrm{R} 528 \mathrm{H}^{m / m}$ mice, respectively. The $\mathrm{R} 528 \mathrm{H}^{+/ m}$ mice were viable, developed normally, bred successfully, and were maintained in the $129 / \mathrm{SV}$ strain with the neomycin-deleted line. In crosses with WT mice, the progeny at 4 weeks were $52 \%$ WT and $47 \% \mathrm{R} 528 \mathrm{H}^{+/ m}$ $(n=99)$. Crosses between heterozygous mice yielded viable homozygous mutant offspring at the expected Men-

Expression of the Cav 1.1 R528H allele at the RNA level was confirmed by first-strand cDNA synthesis from skeletal muscle and PCR amplification with allele-specific primers (Figure 1D). The primers were complementary to sequences in exon 11 (forward, allele-specific) and exon 12 (reverse) that are separated by $9 \mathrm{~kb}$ of genomic sequence, and produced the expected 128-bp amplimer from the cDNA template, thereby excluding the possibility of a false signal from contamination with genomic DNA template. Allele-specific amplification is shown in Figure 1D, wherein a template from WT mice produced a product only when the R-forward primer (R528) was used; conversely, the template from homozygote mutant muscle produced a product only when the $\mathrm{H}$ forward primer (H528) was used. The relative expression levels of the WT and mutant alleles were determined from PCR reactions with 21 cycles of amplification, normalized to a $\beta$-actin amplimer as a control for template quality. Relative transcript levels, compared to the WT allele in normal mice, were $0.41 \mathrm{WT} / 0.57 \mathrm{R} 528 \mathrm{H}$ (for $\mathrm{R} 528 \mathrm{H}^{+/ m}$ mice) and $0.0 \mathrm{WT} / 1.2 \mathrm{R} 528 \mathrm{H}$ (for R528H $\mathrm{H}^{m / m}$ mice). 

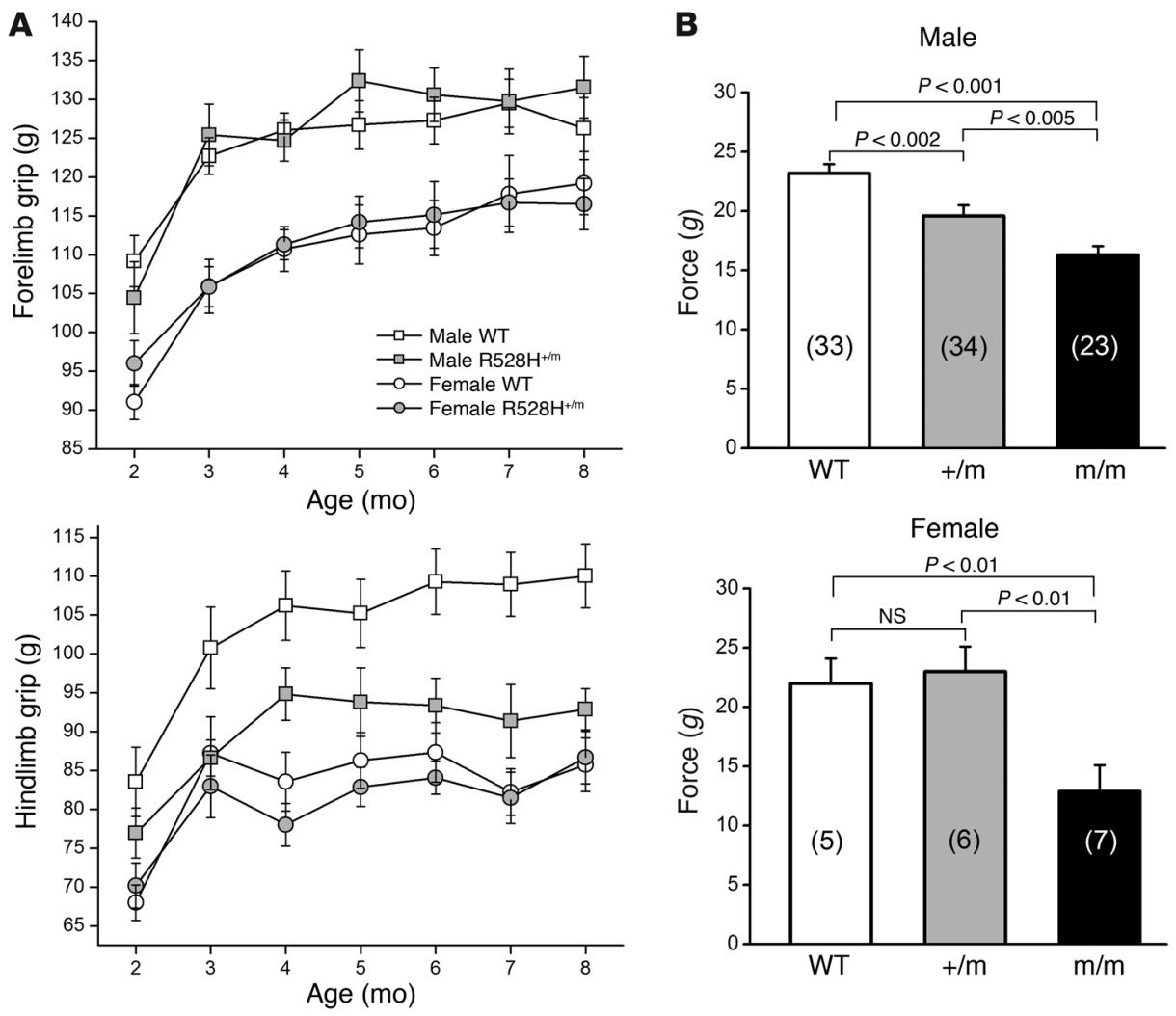

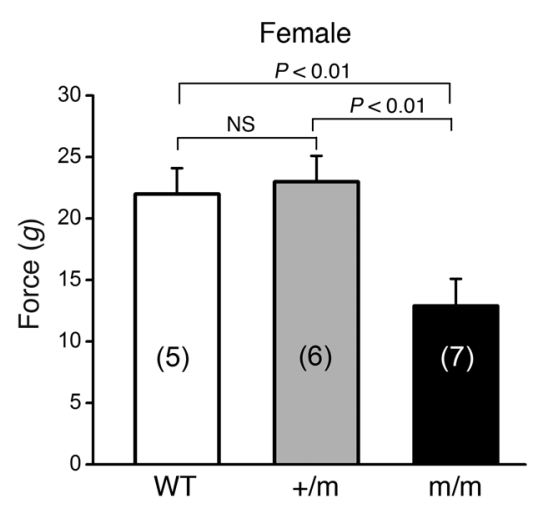

\section{Figure 2}

Muscle force was modestly reduced in $\mathrm{R} 528 \mathrm{H}$ mice. (A) Grip strength was reduced by $10 \%$ in the hindlimb of male heterozygous $\mathrm{R} 528 \mathrm{H}^{+/ m}$ mice $(P<0.005)$, but not in the hindlimb of females or in the forelimb. (B) The peak tetanic force of the EDL in normal $\mathrm{K}^{+}(4.75 \mathrm{mM})$ was reduced in a gene dosage-dependent manner for male $\mathrm{R} 528 \mathrm{H}$ mice and for $\mathrm{R} 528 \mathrm{H} / \mathrm{m}$ females. Numbers within each bar indicate the number of muscles tested.
R528H mice are viable with mild hindlimb weakness. The viability and survival of $\mathrm{R} 528 \mathrm{H}^{+/ m}$ and $\mathrm{R} 528 \mathrm{H}^{m / m}$ mice were indistinguishable from that of WT mice. Feeding behaviors and weight gain over 4-52 weeks were identical for WT and $\mathrm{R} 528 \mathrm{H}^{+/ m}$ mice ( $n=15-20, P>0.3$; Supplemental Figure 1; supplemental material available online with this article; doi:10.1172/JCI66091DS1). No spontaneous attacks of paralysis were observed for $\mathrm{R} 528 \mathrm{H}^{+/ m}$ or $\mathrm{R} 528 \mathrm{H}^{m / m}$ mice, and locomotor activity observed during daylight hours was indistinguishable from that of WT mice. Quantitative grip strength testing revealed a $15 \%$ reduction in hindlimb force for $\mathrm{R} 528 \mathrm{H}^{+/ m}$ males from 3 to 8 months of age $(n=11, P<0.01$; Figure 2A). The reduced grip force for male $\mathrm{R} 528 \mathrm{H}^{+/ m}$ mice did not progressively worsen with age. No differences in grip strength were observed in the forelimbs or in female $\mathrm{R} 528 \mathrm{H}^{+/ m}$ mice. Maximal contractile force was assessed by measuring isometric tension during tetanic stimulation in vitro. The extensor digitorum longus (EDL) muscle from the hindlimb was isolated from 6-month-old mice and maintained at $37^{\circ} \mathrm{C}$. Tetanic contractions were elicited by field stimulation with parallel wire electrodes (1-ms pulses, 250 $\mathrm{Hz}, n=30)$, and curare $(0.25 \mu \mathrm{M})$ was added to block neuromuscular transmission from activation of terminal branches of motor neurons. Peak force in the standard bath containing $4.75 \mathrm{mM}$ $\mathrm{K}^{+}$was reduced for the EDL from male mice $29.7 \%$ decrease for $\mathrm{R} 528 \mathrm{H}^{m / m}, 15.5 \%$ decrease for $\mathrm{R} 528 \mathrm{H}^{+/ m}$ ) compared with WT mice (Figure 2B). In female mice, the EDL peak force was reduced by $41.3 \%$ for homozygous $\mathrm{R} 528 \mathrm{H}^{m / m}$ mice, but there was no difference between heterozygous $\mathrm{R} 528 \mathrm{H}^{+/ m}$ and WT mice (Figure $2 \mathrm{~B}$ ).

In vitro contraction testing reveals a HypoPP phenotype. Susceptibility of HypoPP was assessed by monitoring peak isometric force of the $\mathrm{EDL}$, as the extracellular $\mathrm{K}^{+}$was varied. Force transients recorded at baseline $\left(4.75 \mathrm{mM} \mathrm{K}^{+}\right)$and after exposure to $2 \mathrm{mM} \mathrm{K}^{+}$challenge
(10 and 20 minutes) are shown for individual representative EDL muscles in Figure 3A. The low $\mathrm{K}^{+}$challenge produced only a modest $10 \%$ reduction in EDL peak force for WT mice, whereas muscle from $\mathrm{R} 528 \mathrm{H}^{+/ m}$ and $\mathrm{R} 528 \mathrm{H}^{m / m}$ mice had a marked loss of peak force that decreased by $60 \%$ over 20 minutes. The decay time of the force transient after a tetanic stimulation was not prolonged for the EDL from R528H mice, thereby demonstrating that $\mathrm{Ca}_{V} 1.1$ mutant mice do not have myotonia.

The time course of the onset and recovery for the reduction in EDL force during a 30-minute exposure to $2 \mathrm{mM} \mathrm{K}^{+}$was determined by measuring the peak tetanic force every 2 minutes (Figure $3 \mathrm{~B})$. Both gene dosage of the R528H allele and sex affected the susceptibility to loss of muscle force in low $\mathrm{K}^{+}$. Muscle from homozygous $\mathrm{R} 528 \mathrm{H}^{m / m}$ mice (male or female) had a rapid, $60 \%$ decline in force within 6 minutes and incomplete recovery after return to $4.75 \mathrm{mM} \mathrm{K}^{+}$. In heterozygous $\mathrm{R}^{2} 28 \mathrm{H}^{+/ m}$ mice, a $2-\mathrm{mM} \mathrm{K}^{+}$challenge caused a slight loss of force in EDL for females that was comparable to that of WT mice, but the EDL from males had a slowly progressive loss of force over 30 minutes that approached the $60 \%$ reduction for homozygous mice. A full recovery of force after return to normal $\mathrm{K}^{+}$was observed for $\mathrm{R} 528 \mathrm{H}^{+/ m}$ mice. Spontaneous recovery of force during the low $\mathrm{K}^{+}$challenge was not observed for $\mathrm{R} 528 \mathrm{H}^{+/ m}$ or $\mathrm{R} 528 \mathrm{H}^{m / m}$ mice, in contrast to the large-amplitude, slow oscillations in peak force we previously reported for the sodium channel ( $\left.\mathrm{Na}_{\mathrm{V}} 1.4 \mathrm{R} 669 \mathrm{H}\right)$ HypoPP mouse model (22).

The dose-response relation for peak tetanic force of the EDL over a range of $\mathrm{K}^{+}$concentrations was measured for male $\mathrm{R} 528 \mathrm{H}$ mice and compared with that of WT mice (Figure 3C). The EDL from WT mice tolerated a wide range of $\mathrm{K}^{+}$concentrations, with less than a $20 \%$ reduction in force over 2 to $10 \mathrm{mM}$. In contrast, a pronounced $50 \%$ loss of force was observed for homozygous 


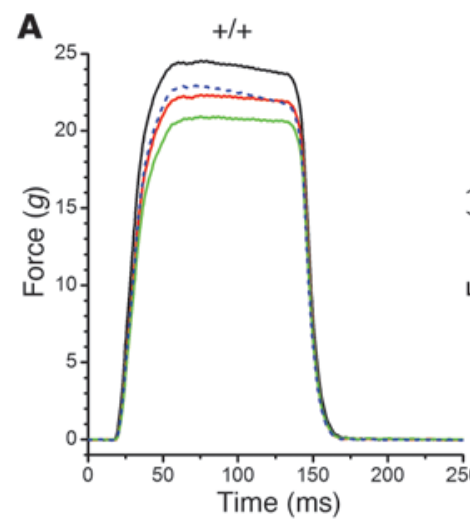

B

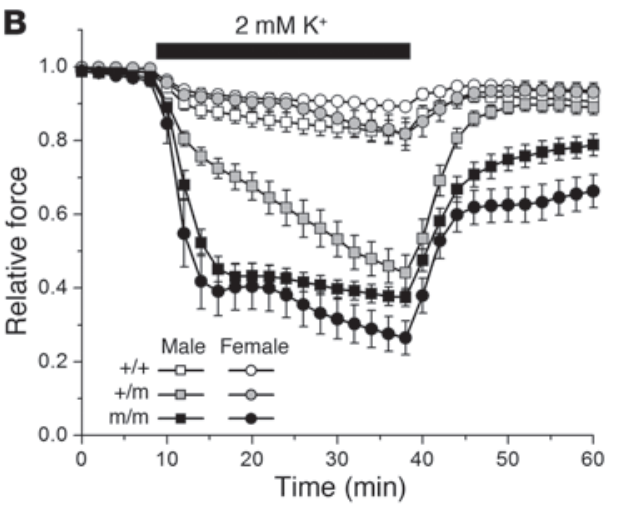

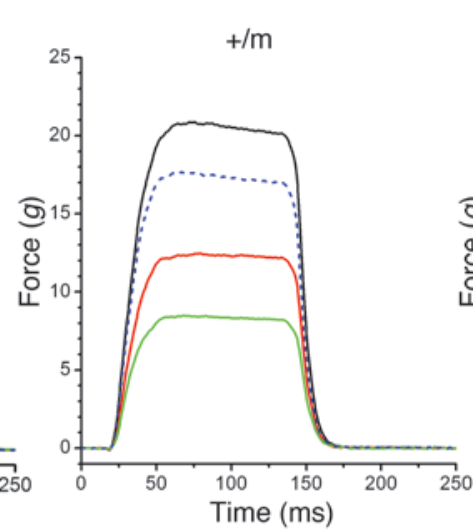
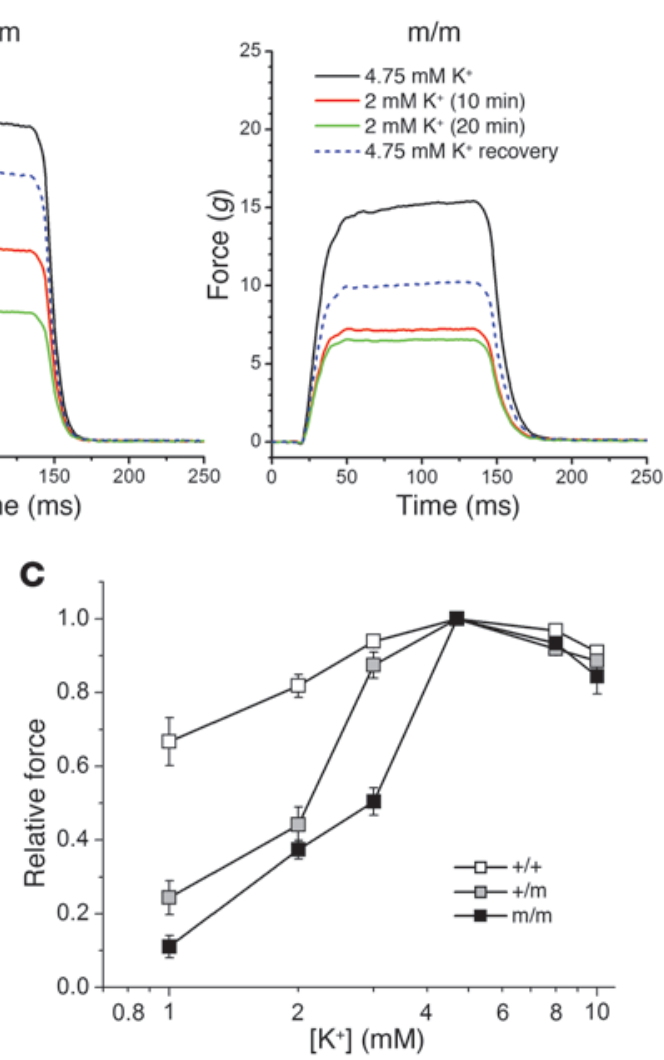

Figure 3

Low- $\mathrm{K}^{+}$challenge reveals a HypoPP phenotype. (A) Muscle force transients in response to in vitro tetanic stimulation of the EDL. Contractions were recorded in normal $\mathrm{K}^{+}\left(4.75 \mathrm{mM}\right.$, black trace) and following exposure to $2 \mathrm{mM} \mathrm{K}^{+}$for 10 minutes (red trace) and 20 minutes (green trace) and subsequent return to $4.75 \mathrm{mM} \mathrm{K}^{+}$for 10 minutes (blue dashed trace). All muscles were from male mice, and each trace is for a single trial. (B) Onset and recovery for loss of EDL force during a 30-minute exposure to $2 \mathrm{mM} \mathrm{K}^{+}$was monitored by performing a tetanic contraction test every 2 minutes. Data show relative peak force, averaged from responses in 5 to 8 muscles. A pronounced loss of force occurred for EDL muscle from $\mathrm{R} 528 \mathrm{H}$ males and had a more rapid onset in homozygotes. Responses in female R528H heterozygotes were comparable to WT, whereas $\mathrm{R} 528 \mathrm{H}^{\mathrm{m} / \mathrm{m}}$ females demonstrated a loss of force with low $\mathrm{K}^{+}$. (C) Dose response curve for minimum force during 30-minute exposures to various $\mathrm{K}^{+}$challenges; all data are from males.

$\mathrm{R} 528 \mathrm{H}^{m / m}$ EDL in $3 \mathrm{mM} \mathrm{K}^{+}$, and a $90 \%$ loss was observed in $1 \mathrm{mM}$ $\mathrm{K}^{+}$. Muscle from heterozygous $\mathrm{R} 528 \mathrm{H}^{+/ m}$ mice had a milder phenotype - onset of a substantial reduction in force was observed with 2 to $3 \mathrm{mM} \mathrm{K}^{+}$. Conversely, the responses of the R528H EDL to high $\mathrm{K}^{+}$challenges of 8 to $10 \mathrm{mM}$ were identical to those of WT EDL and thereby excluded a phenotype of hyperkalemic periodic paralysis. These in vitro data using a provocative $\mathrm{K}^{+}$challenge show a clear HypoPP phenotype, with the susceptibility to loss of muscle force being dependent on dosage of the mutant R528H allele.

In vivo loss of muscle excitability and force due to glucose plus insulin challenge. Susceptibility to attacks of HypoPP in vivo was assessed by provocative testing with i.v. infusion of glucose plus insulin, which promotes transient hypokalemia and has been used for diagnostic testing in humans (2). As in our previous study with $\mathrm{Na}_{V}$ 1.4 HypoPP mice (22), animals were preconditioned with an oral K-binding resin (Kayexalate) that reduced the baseline serum $\mathrm{K}^{+}$to $2.7 \pm 0.10 \mathrm{mM}(n=37$; no difference between WT and $\mathrm{R} 528 \mathrm{H}$ mice) but did not elicit attacks of paralysis. Mice were continuously anesthetized with isoflurane, and the sciatic nerve was stimulated to monitor muscle electrical excitability and force generation. The compound muscle action potential (CMAP) and twitch force of the hindlimb calf muscles (gastrocnemius and soleus) were recorded simultaneously (Figure 4A). The baseline CMAP amplitude, before infusion, was reduced by more than $50 \%$ in both $\mathrm{R} 528 \mathrm{H}^{+/ m}$ and $\mathrm{R} 528 \mathrm{H}^{m / m}$ mice, with no sex bias (Figure 4B). Commensurate with the reduced fiber electrical excitability, the baseline twitch force was lower in $\mathrm{R} 528 \mathrm{H}$ mice, although the difference from WT $(19.8 \pm 2.5 \mathrm{~g}, n=8)$ was statistically demonstrated only for $\mathrm{R} 528 \mathrm{H}^{m / m}$ mice $\left(\mathrm{R} 528 \mathrm{H}^{m / m}: 11.5 \pm 1.9 \mathrm{~g}, n=9, P<0.05\right.$; $\left.\mathrm{R} 528 \mathrm{H}^{+/ m}: 17.0 \pm 2.3 \mathrm{~g}, n=9, P=0.4\right)$.

Glucose plus insulin challenge by continuous i.v. infusion $(0.5$ $\mathrm{ml} / \mathrm{h}$ ) produced a marked decrease in CMAP amplitude and peak twitch force within minutes for both heterozygous and homozygous R528H mice but not for control animals (Figure 4, A and C). This loss of muscle excitability persisted throughout the 2-hour infusion. A gene dosage effect was observed with a faster and larger amplitude decline for $\mathrm{R} 528 \mathrm{H}^{m / m}$ mice than for $\mathrm{R} 528 \mathrm{H}^{+/ m}$ heterozygotes $(P=0.02)$. Homozygous $\mathrm{R} 528 \mathrm{H}^{m / m}$ mice consistently had a transient $10 \%$ increase in muscle force 10 minutes into the infusion (4 of 6 trials) that was never observed for heterozygous $\mathrm{R} 528 \mathrm{H}^{+/ m}$ animals (Figure 4D). Curiously, there was no detectable increase in CMAP amplitude associated with this larger twitch force (Figure 4A). The increased susceptibility for the HypoPP phenotype in male $\mathrm{R} 528 \mathrm{H}^{+/ m}$ mice observed for the in vitro con- 
A

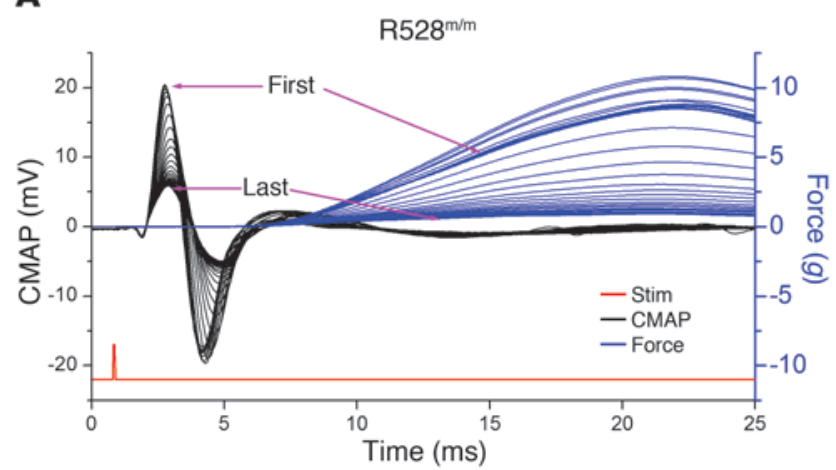

B

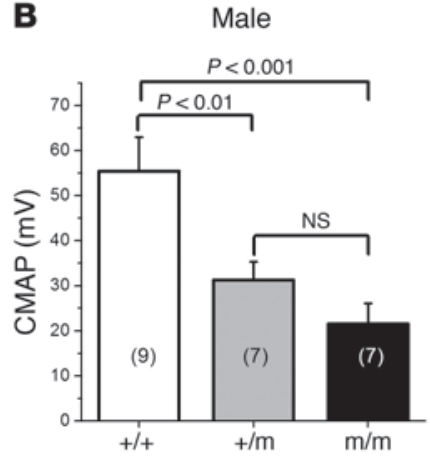

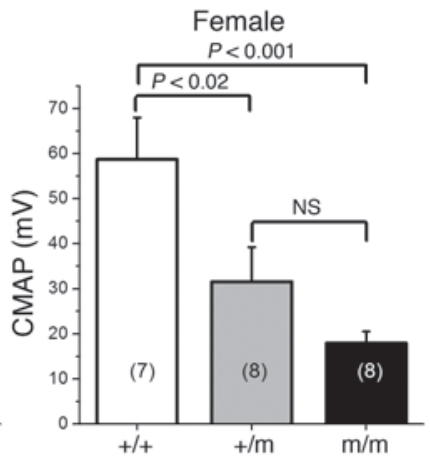
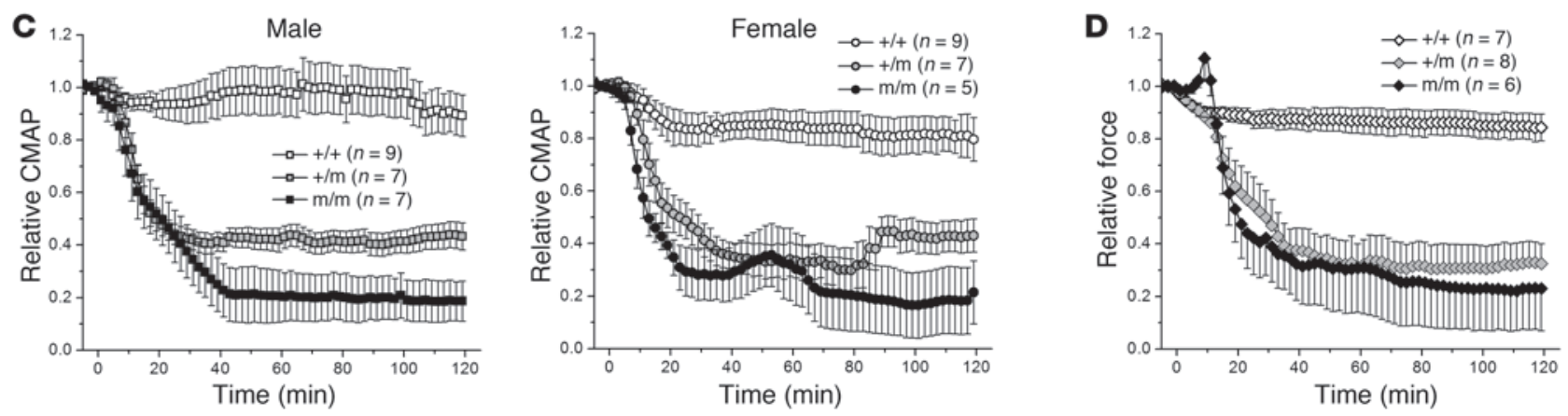

\section{Figure 4}

In vivo HypoPP attack from glucose plus insulin challenge. (A) Each trace shows the muscle force (blue) and CMAP (black) recorded simultaneously in response to a single shock (red) applied to the sciatic nerve. Nerve stimulation was applied once per minute, and each sweep is for a single trial, without averaging. In this $\mathrm{R} 528 \mathrm{H}^{\mathrm{m} / \mathrm{m}}$ mouse, i.v. administration of glucose plus insulin produced a transient increase in peak force during the first 10 minutes, which was followed by a profound decrease in peak force. The peak-peak CMAP amplitude decreased by $75 \%$ during the infusion and did not have an accompanying initial transient increase. (B) Baseline CMAP amplitude (peak-peak) was reduced for both male and female R528H mutant mice. (C) The CMAP amplitude declined by $60 \%$ in $\mathrm{R} 528 \mathrm{H}^{+/ m}$ mice and by $80 \%$ in $\mathrm{R} 528 \mathrm{H}^{\mathrm{m} / m}$ mice during the continuous 2-hour infusion, whereas the CMAP remained stable in WT mice. No differences were observed for the CMAP responses between male and female $\mathrm{R} 528 \mathrm{H}$ mutant mice. (D) The twitch force measured at the Achilles tendon had a commensurate decrease in peak amplitude; data are from male and female mice.

traction tests (Figure 3) and baseline grip force (Figure 2) was not detected with the glucose plus insulin challenge (Figure 4).

Muscle fiber excitability of R528H mice. The transient loss of force during an attack of HypoPP in humans is caused by depolarization of the resting potential that paradoxically occurs in the setting of hypokalemia (3) and inactivates sodium channels to render the fiber inexcitable. We measured $V_{\text {rest }}$ from microelectrode impalement of individual fibers in the soleus muscle maintained at $37^{\circ} \mathrm{C}$ in vitro. In $4.75 \mathrm{mM} \mathrm{K}^{+}, V_{\text {rest }}$ was comparable for WT and heterozygous $\mathrm{R} 528 \mathrm{H}^{+/ m}$ fibers but was depolarized by $15 \mathrm{mV}(P<0.001)$ for homozygous $\mathrm{R} 528 \mathrm{H}^{m / m}$ muscle (Figure $5 \mathrm{~A}$ ). More importantly, in response to a hypokalemic challenge of $2 \mathrm{mM} \mathrm{K}^{+}$, WT fibers hyperpolarized as expected from the negative shift in the Nernst potential for $\mathrm{K}^{+}$, whereas the $\mathrm{R} 528 \mathrm{H}$ fibers paradoxically depolarized (Figure $5 \mathrm{~A})$. The intrinsic excitability of fibers was ascertained by injecting a holding current to set $V_{\text {rest }}$ at $-85 \mathrm{mV}$ and then eliciting action potentials by applying 2-ms current pulses of varying intensity. The holding current compensated for differences in $V_{\text {rest }}$, which otherwise would have a strong influence on sodium channel availability. No differences in action potential amplitude, threshold, maximal rate of rise, or duration were observed between WT and $\mathrm{R} 528 \mathrm{H}^{+/ m}$ or $\mathrm{R} 528 \mathrm{H}^{m / m}$ fibers (Figure $5 \mathrm{~B}$ ). In contrast, our HypoPP mouse model with a $\mathrm{Na}_{\mathrm{v}} 1.4 \mathrm{R} 669 \mathrm{H}$ mutation had a reduced spike ampli- tude, slower rate of rise, and prolonged duration, consistent with a reduction in sodium channel availability (22).

Anomalous inward current in R528H fibers. While it has been known for decades that a depolarized shift of $V_{\text {rest }}$ produces the loss of excitability during an attach of HypoPP (3), the identity of the current(s) that cause this shift has been elusive. The paradoxical depolarization in low $\mathrm{K}^{+}$is not prevented by drugs that block the ion-conducting pore of mutant channels (tetrodotoxin for $\mathrm{Na}_{V} 1.4$ HypoPP or nitrendipine for $\left.\mathrm{Ca}_{V} 1.1 \mathrm{HypoPP}\right)(24,25)$. The remarkable clustering of HypoPP mutations at arginine residues in the S4 voltage sensors of $\mathrm{Na}_{V} 1.4$ or $\mathrm{Ca}_{V} 1.1$ implicate a common mechanism wherein these $\mathrm{S} 4$ mutations create a voltage-dependent leak or gating pore current $(16,17)$. Indeed, gating pore currents have been demonstrated for all $6 \mathrm{Na}_{V} 1.4$ HypoPP mutations tested in oocytes (21) and in muscle fibers from our knockin $\mathrm{Na}_{V} 1.4$ $\mathrm{R} 669 \mathrm{H}$ HypoPP mouse (22). The poor expression of $\mathrm{Ca}_{V} 1.1$ in heterologous systems has precluded the ability to test whether $\mathrm{Ca}_{V} 1.1$ HypoPP mutant channels support anomalous gating pore currents. We recorded steady-state ionic currents in voltage-clamped fibers (flexor digitorum brevis and lumbricales) from R528 $\mathrm{H}^{\mathrm{m} / m}$ mice to search for evidence of a gating pore current. As in our prior studies with $\mathrm{Na}_{V} 1.4$ HypoPP fibers (22), a mixture of blockers (tetrodotoxin, $\mathrm{Ba}^{2+}, \mathrm{Co}^{2+}$, 4-aminopyridine, 9-anthracene carboxyl- 

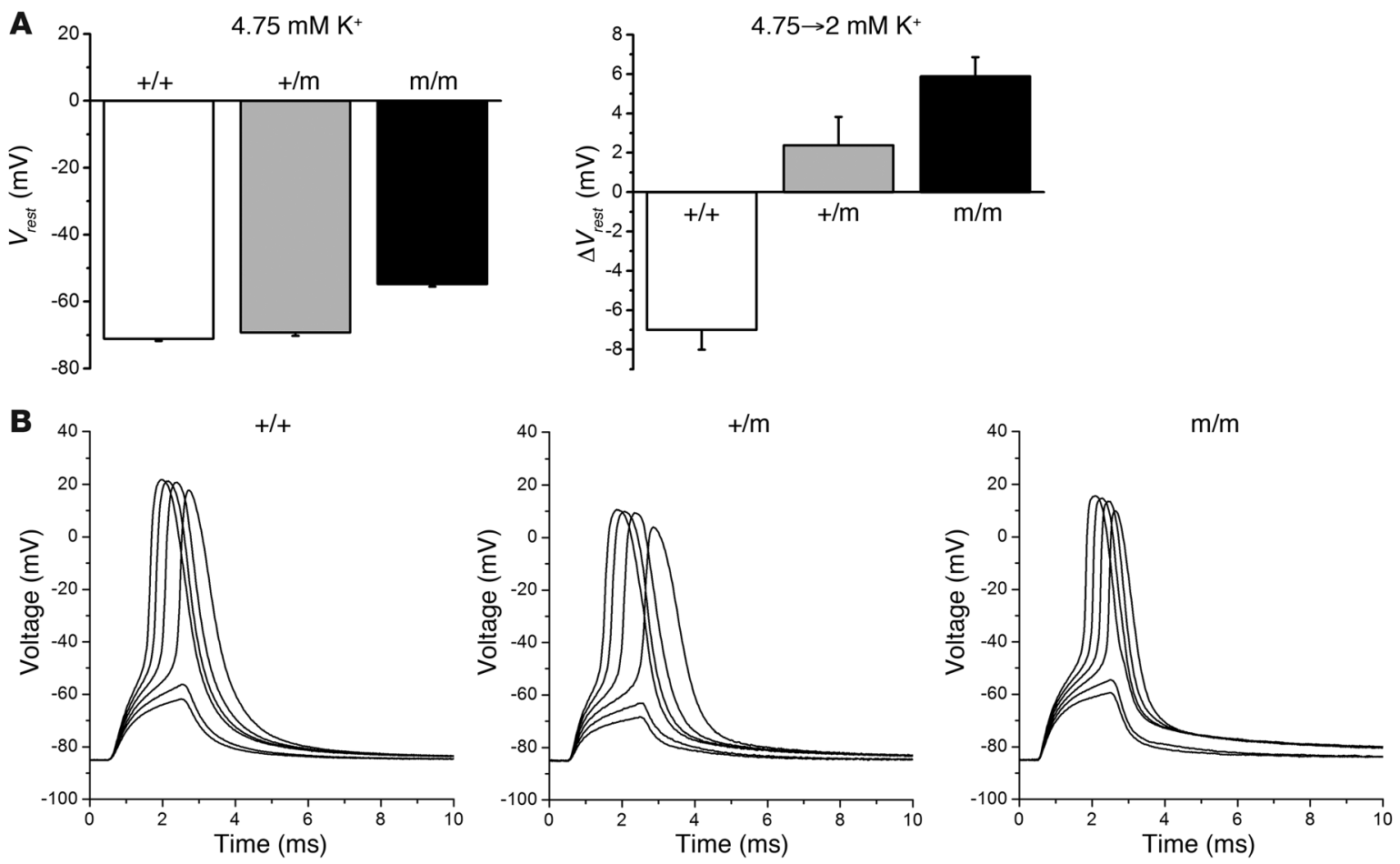

\section{Figure 5}

Reduced excitability of $\mathrm{R} 528 \mathrm{H}$ fibers is caused by depolarization of $V_{\text {rest. }}$ (A) The resting potential in $4.75 \mathrm{mM} \mathrm{K+}$ was comparable for WT $(-71.1 \pm 0.68 \mathrm{mV}, n=509)$ and $\mathrm{R} 528 \mathrm{H}^{+/ m}(-69.2 \pm 1.0 \mathrm{mV}, n=166)$ soleus muscle but depolarized in $\mathrm{R} 528 \mathrm{H}^{\mathrm{m} / \mathrm{m}}$ muscle $(-54.8 \pm 0.75 \mathrm{mV}$, $n=216)$. Bath exchange to $2 \mathrm{mM} \mathrm{K}^{+}$for the same muscle specimens caused a hyperpolarization $(-7.0 \pm 1.0 \mathrm{mV})$ for WT fibers, whereas $\mathrm{R} 538 \mathrm{H}$ fibers depolarized by $2.4 \pm 1.4 \mathrm{mV}\left(\mathrm{R} 528 \mathrm{H}^{+/ m}\right)$ and $5.9 \pm 0.98 \mathrm{mV}\left(\mathrm{R} 528 \mathrm{H}^{\mathrm{m} / \mathrm{m}}\right)$. (B) A holding current was applied to set $V_{\text {rest }}$ at $-85 \mathrm{mV}$ in dissociated single fibers, and action potentials were elicited by the application of 2-ms current pulses of increasing intensity. Under these conditions, the threshold, amplitude, rate of rise, and duration of action potentials were identical for $\mathrm{WT}, \mathrm{R} 528 \mathrm{H}^{+/ m}$, and $\mathrm{R} 528 \mathrm{H}^{m / m}$ fibers.

ic acid) and a Cl-free bath were used to suppress $\mathrm{Na}^{+}, \mathrm{K}^{+}, \mathrm{Ca}^{2+}$, and $\mathrm{Cl}^{-}$currents conducted through the central pore of these channels. The sensitivity for detecting gating pore currents was further increased by subtracting the remaining nonspecific currents after the addition of $3.5 \mathrm{mM} \mathrm{La}^{3+}$, which is known to block gating pore currents in mutant $\mathrm{Na}_{V} 1.4$ channels $(17,21)$. In comparison with WT fibers, the $\mathrm{La}^{3+}$-sensitive currents recorded from $\mathrm{R} 528 \mathrm{H}^{\mathrm{m} / m}$ fibers had a larger inward component (i.e., negative amplitude) at all test potentials below $-55 \mathrm{mV}(P<0.05$; Figure 6A). Subtraction of the current-voltage response measured in WT fibers from the response measured in $\mathrm{R} 528 \mathrm{H}^{m / m}$ fibers revealed an anomalous inward current in HypoPP muscle (Figure 6B) that had modest rectification (inward current at negative potentials was larger than outward current at more positive potentials; Figure 6B). These biophysical features are consistent with a voltage-dependent gating pore current in which the anomalous pathway for ion conduction was permissive at negative potentials (Figure 6C) but was closed by movement of the $\mathrm{S} 4$ voltage sensor at depolarized potentials. The peak conductance of the inward gating pore current was $28 \mathrm{nS} / \mathrm{nF}$ in $\mathrm{R} 528 \mathrm{H}^{m / m}$ fibers, which was comparable to the magnitude of gating pore currents detected in $\mathrm{Na}_{v} 1.4$ HypoPP muscle, $7 \mathrm{nS} / \mathrm{nF}$ in heterozygous $\mathrm{R} 528 \mathrm{H}^{+/ m}$ fibers (22), and which in computational models is sufficient to cause susceptibility to depolarization of $V_{\text {rest }}$ in low $\mathrm{K}^{+}(23)$.

Loss of function defect for $\mathrm{C}_{V} 1.1 \mathrm{R} 528 \mathrm{H}$ currents. Ionic currents conducted by the central pore of $\mathrm{Ca}_{V} 1.1$ channels were measured by 2-electrode voltage clamp from short muscle fibers dissociated from the footpad (flexor digitorum brevis and lumbricales). The charge carrier was $2 \mathrm{mM} \mathrm{Ba}^{2+}$ to facilitate block of inward rectifier $\mathrm{K}$ channels and minimize $\mathrm{Ca}^{2+}$ activated conductances. Currents were recorded in a tetraethyl ammonium $(140 \mathrm{mM})$, sodium-free, chloride-free solution to suppress chloride and sodium currents. Inward $\mathrm{Ba}^{2+}$ currents were activated at potentials of -40 $\mathrm{mV}$ or greater and peaked at $-15 \mathrm{mV}$ (Figure 7A). Compared with responses in WT fibers, the current density was reduced by $53 \%$ in $\mathrm{R} 528 \mathrm{H}^{m / m}$ fibers $(n=23, P<0.001)$ and averaged $10 \%$ lower in heterozygous $\mathrm{R} 528 \mathrm{H}^{+/ m}$ fibers, although this difference was not significant. The current-voltage relation was fit with an Ohmic conductance $\left(G_{\max }\right)$ scaled by a voltage-dependent gating term (Figure $7 \mathrm{~A}) ; \mathrm{I}=\mathrm{G}_{\max }\left(\mathrm{V}-\mathrm{E}_{\text {rev }}\right) /\left[1+\exp \left(\mathrm{V}-\mathrm{V}_{1 / 2}\right) / \mathrm{K}\right]$, where $\mathrm{E}_{\text {rev }}$ is the reversal potential, $V_{1 / 2}$ is the midpoint for voltage-dependent activation, and $\mathrm{K}$ is a steepness factor. As expected from the peak inward current values, the maximum conductance, $G_{\max }$, was reduced in $\mathrm{R} 528 \mathrm{H}^{\mathrm{m} / m}$ fibers $(146 \pm 9 \mathrm{nS} / \mathrm{nF}, n=20)$ compared with WT fibers (309 $\pm 14 \mathrm{nS} / \mathrm{nF}, n=23)$, while only a modest reduction occurred in $\mathrm{R} 528 \mathrm{H}^{+/ m}$ fibers $(280 \pm 12 \mathrm{nS} / \mathrm{nF}, n=23)$. To compare the voltage dependence for activation of $\mathrm{Ca}_{v} 1.1$ channels more clearly, current density was divided by $\mathrm{G}_{\max }\left(\mathrm{V}-\mathrm{E}_{\mathrm{rev}}\right)$ to compute the relative conductance (Figure $7 \mathrm{~B}$ ). The modest difference in midpoint of activation $\left(\mathrm{V}_{1 / 2}\right)$, reflected by the shift along the voltage axis, was not significant (ANOVA with Bonferroni correction). The voltage dependence was steeper, however, for WT fibers 

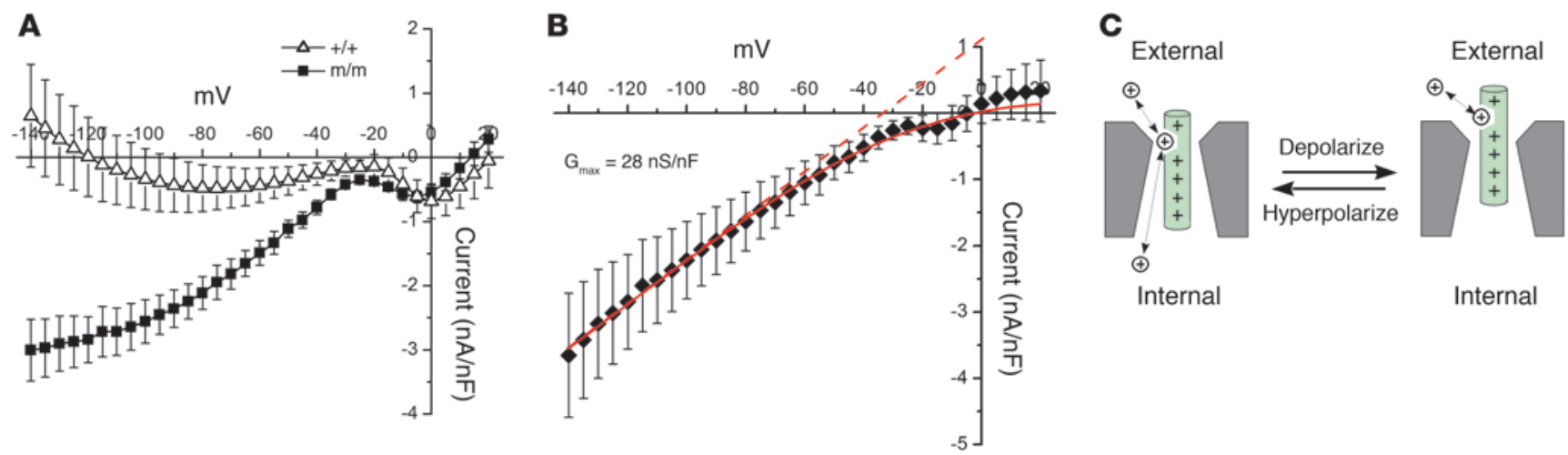

\section{Figure 6}

Detection of a gating pore current in $\mathrm{R} 528 \mathrm{H}^{\mathrm{m} / \mathrm{m}}$ fibers. (A) Voltage dependence of the $\mathrm{La}^{3+}$-sensitive current recorded at steady state showed an increased inward current at negative potentials for R528 $\mathrm{H}^{\mathrm{m} / \mathrm{m}}$ fibers $(n=6)$ compared with WT fibers $(n=15)$. (B) Subtraction of the mean responses in A revealed an inward-rectifying current in R528H fibers. The dashed line indicates a linear conductance of $28 \mathrm{nS} / \mathrm{nF}$. (C) Schematic diagram illustrating the voltage dependence of the gating pore current produced by mutation of an arginine in the outer face of the S4 voltage sensor.

$(P<0.001)$, as reflected by a smaller value of $\mathrm{K}$ (WT: $4.4 \pm 0.19$ $\mathrm{mV}, \mathrm{n}=23 ; \mathrm{R} 528 \mathrm{H}^{+/ m}: 5.3 \pm 0.10 \mathrm{mV} ; \mathrm{R} 528 \mathrm{H}^{m / m}: 5.3 \pm 0.2 \mathrm{mV}$, $n=20)$. The time course of activation was about 2 -fold slower for $\mathrm{R} 528 \mathrm{H}^{m / m}$ (time constant of $14.7 \pm 0.67 \mathrm{~ms}$ for $\mathrm{R} 528 \mathrm{H}^{m / m}$ versus $6.8 \pm 0.62 \mathrm{~ms}$ for WT; $P<0.0001$ ), as shown by the superposition of amplitude-normalized currents elicited at $0 \mathrm{mV}$ (Figure 7C).

The level of $\mathrm{Ca}_{V} 1.1$ expression at the membrane was estimated by measuring the small current transient associated with movement of the channel voltage sensors. This so-called gating charge displacement was measured in a bath containing $\mathrm{Co}^{2+}(1 \mathrm{mM})$ and $\mathrm{La}^{3+}(0.1 \mathrm{mM})$ to block ionic currents conducted by $\mathrm{Ca}_{\mathrm{V}} 1.1$. The voltage dependence of the gating charge displacement is shown in Figure 7D. The charge displacement saturates at depolarized potentials where all available voltage sensors have shifted to the active state conformation. The total charge displacement was reduced in $\mathrm{R} 528 \mathrm{H}$ fibers $\left(\mathrm{R} 528 \mathrm{H}^{m / m}: 21.4 \pm 1.5 \mathrm{pC} / \mathrm{nF}, n=19\right.$, $P<0.001 ; \mathrm{R} 528 \mathrm{H}^{+/ m}: 28.2 \pm 1.5 \mathrm{pF} / \mathrm{nC}, n=23, P<0.02$; WT: $32.6 \pm 1.2 \mathrm{pF} / \mathrm{nC}, n=34$ ), consistent with reduced membrane expression compared with WT. The relative decrease in peak ionic current for R528H $\mathrm{H}^{m / m}$ fibers (53\%; Figure 7A) was substantially greater than the relative decrease in charge displacement (36\%; Figure 7D). This discrepancy implies that the reduced ionic current density cannot be entirely accounted for by a lower expression level of $\mathrm{R} 528 \mathrm{H}^{m / m}$ at the membrane. One possibility is the $\mathrm{R} 528 \mathrm{H}$ mutation partially decouples voltage sensor movement to the opening of the $\mathrm{Ca}_{\mathrm{V}} 1.1$ pore.

Excitation-contraction coupling is disrupted in R528H mice. Translocation of the voltage sensors in $\mathrm{Ca}_{\mathrm{V}} 1.1$ is coupled to opening of the sarcoplasmic reticulum (SR) calcium release channel or ryanodine receptor RYR1 $(26,27)$. Since the $\mathrm{R} 528 \mathrm{H}$ mutation is in the domain II voltage sensor, we assessed the integrity of excitationcontraction coupling by recording voltage-dependent myoplasmic $\mathrm{Ca}^{2+}$ transients with fluorescent dyes. Calcium transients elicited by field stimulation (parallel extracellular wires) of dissociated flexor digitorum brevis (FDB) fibers were markedly reduced for R528H $\mathrm{H}^{m / m}$ fibers (Figure 8A). Fibers from heterozygous $\mathrm{R} 528 \mathrm{H}^{+/ m}$ mice had modestly reduced peak transients with a slower activation. To control for the possibility that a lower (depolarized) resting potential in $\mathrm{R} 528 \mathrm{H}$ fibers might reduce fiber excitability and thereby impair $\mathrm{Ca}^{2+}$ release, we measured $\mathrm{Ca}^{2+}$ transients in volt- age-clamped fibers. On average, the amplitude of the $\mathrm{Ca}^{2+}$ transient under voltage clamp conditions was 3 -fold smaller in $\mathrm{R} 528 \mathrm{H}^{\mathrm{m} / \mathrm{m}}$ fibers compared with WT (Figure 8, B and D). For heterozygous $\mathrm{R} 528 \mathrm{H}^{+/ m}$ fibers, the amplitude was comparable to that of WT, but the rise time was slower (compare responses at $+20 \mathrm{mV}$ in Figure 8, $\mathrm{B}$ and C). Mutations of the Cav1.1-RyR-1 complex may also cause an SR leak with elevated resting myoplasmic $\mathrm{Ca}^{2+}$ and decreased SR Ca ${ }^{2+}$ content $(28,29)$. These changes were not observed in $\mathrm{R} 528 \mathrm{H}^{m / m}$ fibers, where the resting $\mathrm{Ca}^{2+}$ was lower $(80.5 \pm 7 \mathrm{nM})$ than for WT $(123 \pm 12 \mathrm{nM})$. The total SR Ca ${ }^{2+}$ content, measured with Fluo-4FF in response to pharmacologic release with 4-CMC, was indistinguishable between WT and $\mathrm{R}^{2} 28 \mathrm{H}^{+/ m}(P=0.8)$ and between WT and R528H $\mathrm{H}^{m / m}(P=0.3)$.

Vacuolar myopathy in R528H fibers. Morphological studies were performed on the tibialis anterior (TA) and gastrocnemius muscles. Mild, nonspecific changes were observed in R528H $\mathrm{m} / \mathrm{m}$ fibers from the TA of 9-month-old animals, with scattered central nuclei and rare vacuoles (data not shown). No changes in fiber type distribution were noted. Histological studies on frozen sections from the gastrocnemius muscle in 4-month-old mice showed marked vacuolar changes with centrally located clear vesicles in $\mathrm{R} 528 \mathrm{H}^{\mathrm{m} / \mathrm{m}}$ fibers (Figure 9A). Ultrastructural studies showed disruption of the triad junctions in $\mathrm{R} 528 \mathrm{H}^{\mathrm{m} / \mathrm{m}}$ fibers, with massive dilation of the transverse tubules and cisternae of the sarcoplasmic reticulum (Figure 9B). For heterozygous $\mathrm{R} 528 \mathrm{H}^{+/ m}$ mice, mildly dilated cisternae were occasionally seen, but there were no large vacuoles.

\section{Discussion}

The Cav1.1 R528H knockin mutant mouse created a skeletal muscle phenotype that recapitulated all the essential features of HypoPP in humans. Similar to the clinical presentation of HypoPP, the R528H mouse phenotype included: (a) transient episodes of severe weakness triggered by low extracellular $\mathrm{K}^{+}$, (b) ictal loss of muscle excitability, (c) mild permanent weakness of some muscle groups, (d) absence of myotonia, (e) vacuolar myopathy, and (f) autosomal-dominant inheritance. The in vitro studies of muscle excitability also recapitulated the principal abnormality observed in biopsied human fibers (3) - namely, a paradoxical depolarization of the resting potential in response to hypokalemia (Figure $5 \mathrm{~A})$. Moreover, the phenotype was more severe in male R528H mice, 
A

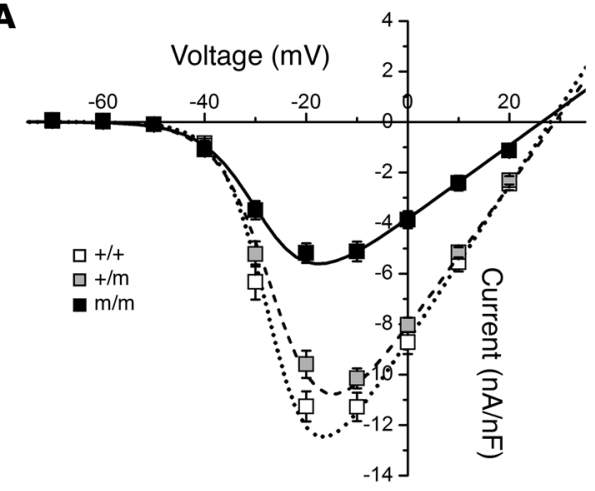

C

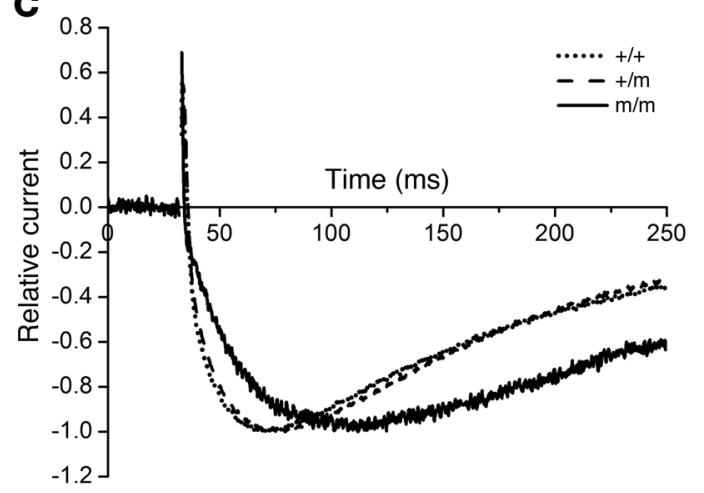

B

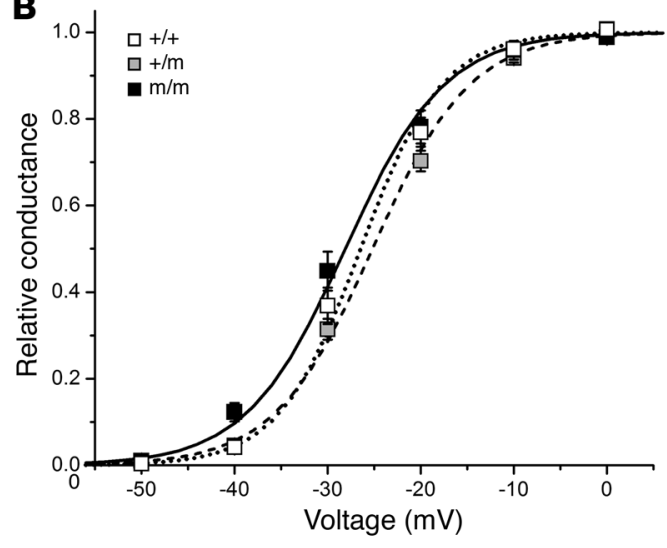

D

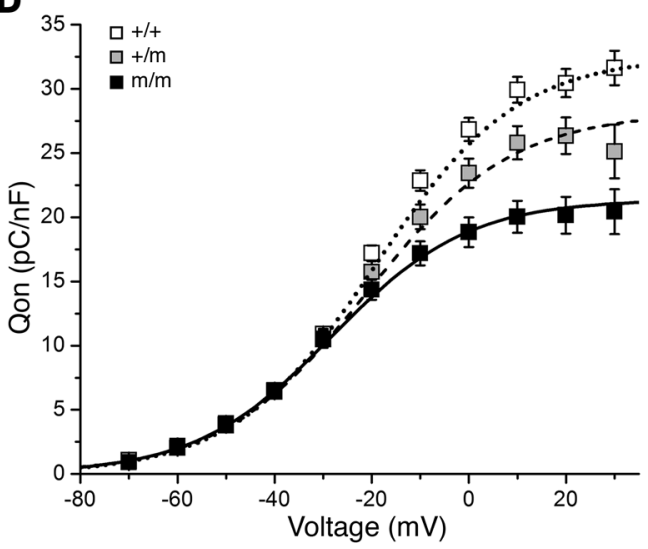

Figure 7

Loss-of-function changes for ionic current conducted by CaV1.1 R528H channels. (A) Peak current-voltage relationship measured in dissociated FBD fibers with $2 \mathrm{mM} \mathrm{Ba}^{2+}$ as the charge carrier showed a $53 \%$ reduction in current density for $\mathrm{R} 528 \mathrm{H}^{\mathrm{m} / \mathrm{m}}$ fibers. (B) Transformation of peak current to relative conductance showed the voltage dependence of activation was comparable for WT and $\mathrm{R} 528 \mathrm{H}$ channels. (C) Ba ${ }^{2+}$ currents elicited by depolarization from $-100 \mathrm{mV}$ to $0 \mathrm{mV}$ were amplitude normalized to the peak inward current to illustrate the rate of activation was slower by $50 \%$ for R528 $\mathrm{H}^{\mathrm{m} / \mathrm{m}}$ channels. The relative slowing for the rate of activation in $\mathrm{R} 528 \mathrm{H}^{\mathrm{m} / \mathrm{m}}$ fibers was observed over the entire range of test potentials from $-30 \mathrm{mV}$ to $20 \mathrm{mV}$. The fast outward transient was the charge displacement current from translocation of the voltage sensors. (D) Voltage dependence for outward displacement of the voltage sensor charge with membrane depolarization (Qon). The maximal charge displacement was reduced by $36 \%$ in $\mathrm{R} 528 \mathrm{H}^{\mathrm{m} / \mathrm{m}}$ fibers. The reduction in charge displacement for $\mathrm{R} 528 \mathrm{H}$ was less than the reduction in ionic current density, implying that the mutation disrupts coupling of voltage sensor movement to channel opening.

and this sex bias is most prominent for the R528H mutation, compared with other Cav1.1 mutations in human $\mathrm{HypoPP}(4,6)$.

The availability of an animal model provided an opportunity to further characterize the HypoPP phenotype by means that are not feasible in human studies. Matings of heterozygous R $528 \mathrm{H}^{+/ m}$ mice produced viable homozygous mutant mice that had a more severe phenotype with a greater baseline reduction in muscle force and excitability (CMAP; Figure 4B) as well as increased susceptibility to acute exacerbations in a low $\mathrm{K}^{+}$challenge. This gene dosage effect implies incomplete dominance of the mutant allele for inheritance of the HypoPP trait. Our interpretation is that 1 copy of the R528H allele produced a gain-of-function defect, the gating pore leakage current (Figure 6), that was sufficient to cause susceptibility to HypoPP but did not cause a dominant-negative suppression of Cav1.1 from the normal allele. In homozygous R528H $\mathrm{m} / \mathrm{m}$ mice, the magnitude of the leakage current was doubled and thereby created a more severe phenotype. The availability of fully differentiated muscle fibers from the $\mathrm{R} 528 \mathrm{H}$ mouse provided the ability to construct a dose-response association for the $\mathrm{K}^{+}$-dependent loss of muscle force that has not previously been possible using limited human HypoPP biopsies. For the heterozygous R $528 \mathrm{H}^{+/ m}$ mouse, which is the ortholog for human HypoPP, muscle force steeply declined as the $\mathrm{K}^{+}$concentration was lowered below $3 \mathrm{mM}$ (Figure 3C). Loss of force occurred in homozygous R $528 \mathrm{H}^{\mathrm{m} / \mathrm{m}}$ muscle for $\mathrm{K}^{+}$levels less than $4 \mathrm{mM}$ and was $50 \%$ of normal at $3 \mathrm{mM}$.

Comparison of $\mathrm{C} a_{V} 1.1$ HypoPP to $\mathrm{Na}_{V} 1.4 \mathrm{HypoPP}$. In humans, the HypoPP phenotypes caused by missense mutations of $\mathrm{Ca}_{\mathrm{V}} 1.1$ or $\mathrm{Nav} 1.4$ are largely overlapping. Indeed, the existence of 2 disease genes was not anticipated on the basis of clinical features from different kindreds. Subsequent to the identification of $S C N 4 A$ as a second causative HypoPP gene encoding $\mathrm{Na}_{\mathrm{v}} 1.4$, a genotype/phenotype analysis revealed some differences (6). HypoPP associated with Cav1.1 mutations has reduced penetrance for episodic attacks of weakness in women, whereas Nav1.4 HypoPP has no sex bias (2). HypoPP due to $\mathrm{Ca}_{v} 1.1$ mutations is frequently associated with vacuolar myopathy, whereas $\mathrm{Na}_{\mathrm{v}} 1.4 \mathrm{HypoPP}$ has transverse tubular aggregates without prominent vacuoles. These disease genespecific differences also occurred in our $\mathrm{Na}_{\mathrm{v}} 1.4 \mathrm{R} 669 \mathrm{H}$ (22) and 

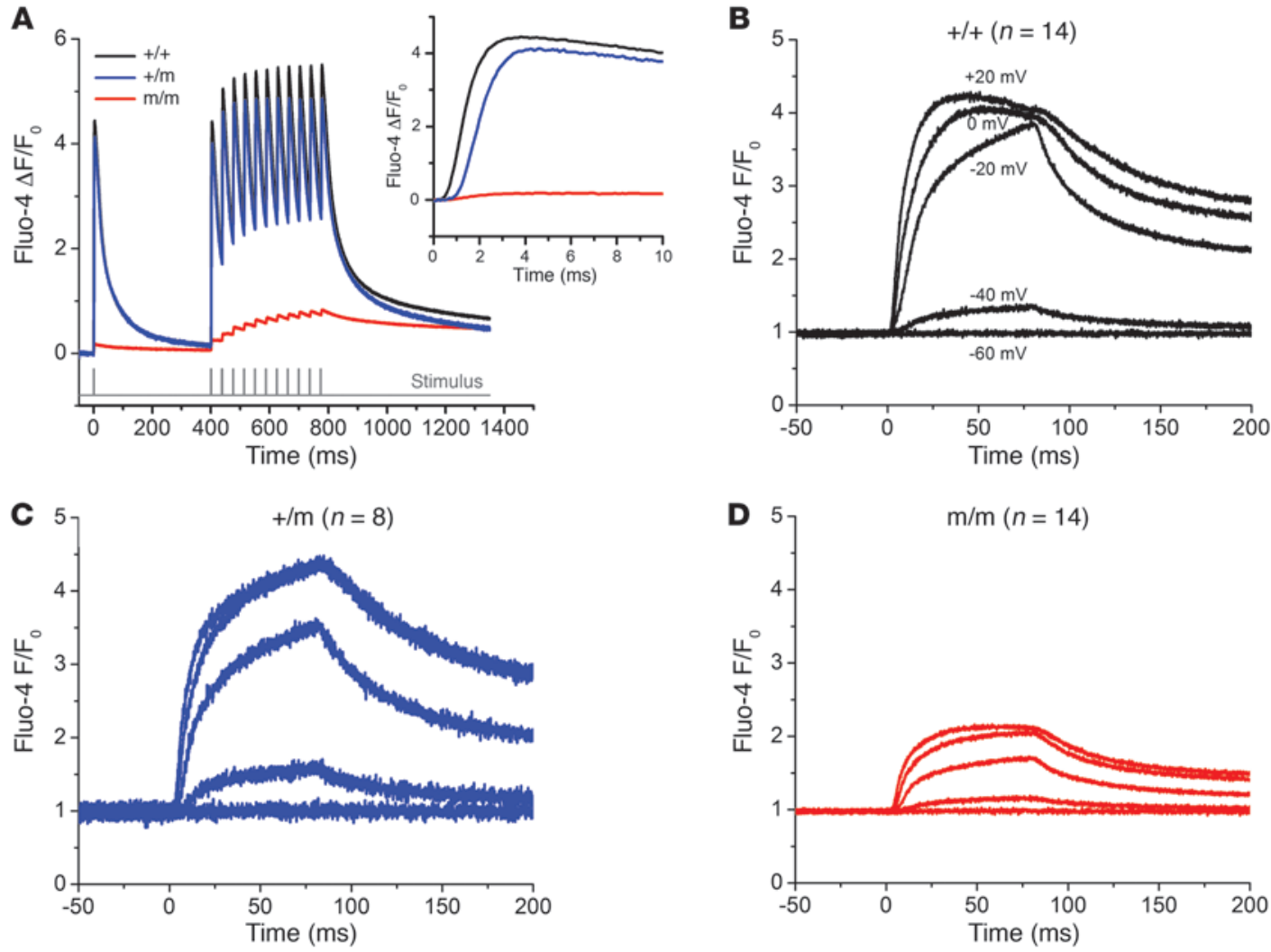

Figure 8

Voltage-dependent $\mathrm{Ca}^{2+}$ release is impaired in $\mathrm{R} 528 \mathrm{H}$ fibers. (A) Calcium transients elicited by field stimulation of isolated FBD fibers loaded with Fluo-4. Traces are averages from $29 \mathrm{WT}, 16 \mathrm{R} 528 \mathrm{H}^{+/ m}$, and $42 \mathrm{R} 528 \mathrm{H}^{\mathrm{m} / m}$ fibers. Inset shows the response to a single shock on an expanded time scale. Fibers from R528H $\mathrm{m} / \mathrm{m}$ mice often failed to contract in response to the stimulus shock. (B) Fluo- 4 transients in WT fibers elicited by step depolarization of $80 \mathrm{~ms}$ from $-100 \mathrm{mV}$ to a range of potentials ( $-60 \mathrm{mV}$ to $20 \mathrm{mV}$ ), as labeled. (C) Fluo-4 transients in FBD fibers from heterozygous $\mathrm{R}_{2} 28 \mathrm{H}^{+/ m}$ mice stimulated with the same voltage clamp protocol as in $\mathbf{B}$. The rate increase for the $\mathrm{Ca}^{2+}$ transient was slower than for WT, although the final amplitude was comparable. (D) Fluo-4 transients recorded from voltage-clamped R528 $\mathrm{H}^{\mathrm{m} / \mathrm{m}} \mathrm{FBD}$ fibers.

$\mathrm{Ca}_{V} 1.1 \mathrm{R} 528 \mathrm{H}$ mouse models of HypoPP. Additional comparisons in our mouse models showed that while susceptibility to loss of force occurred at the same level of hypokalemia (below $3 \mathrm{mM}$ for heterozygotes and $4 \mathrm{mM}$ for homozygotes), there was a difference in susceptibility of specific muscles. For the heterozygous $\mathrm{Na}_{V} 1.4$ $\mathrm{R} 669 \mathrm{H}$ mouse, a $2-\mathrm{mM} \mathrm{K}^{+}$challenge produced a greater reduction in force at 10 minutes for the soleus (30\%) than for the EDL (20\%), whereas in the Cav1.1 R528H mouse a greater reduction occurred for the EDL (30\%) than soleus (15\%). A more striking difference was that $\mathrm{Na}_{\mathrm{V}} 1.4 \mathrm{R} 669 \mathrm{H}$ muscle had large-amplitude oscillations in peak force during the hypokalemic challenge (Figure 2C in ref. 22), which we interpreted as cycles of recovery and recurrent attacks over minutes, but these were never observed in the Cav1.1 R528H muscle. Additional gene-specific differences were observed in the 2 mouse models, as expected from the primary functional roles for $\mathrm{Na}_{V} 1.4$ and $\mathrm{Ca}_{V} 1.1$ in muscle. Fibers in $\mathrm{Na}_{V} 1.4 \mathrm{R} 669 \mathrm{H}$ mice had reduced intrinsic excitability attributable to a decrease in sodium current density, whereas Cav1.1 R528H fibers had normal excitability. Conversely, Cav1.1 R528H fibers had impaired voltagedependent $\mathrm{Ca}^{2+}$ release (Figure 8).

Pathomechanism for acute attacks of weakness in R528H HypoPP. Nearly 3 decades ago, studies on biopsied fibers from HypoPP patients showed that exposure to low extracellular $\mathrm{K}^{+}$caused a paradoxical depolarization of $V_{\text {rest }}$, which inactivates sodium channels and renders the fiber inexcitable (3). The challenge has been to identify the mechanism underlying this shift in membrane potential and to understand how it is triggered by hypokalemia. Following the identification CACNA1S and SCN4A as HypoPP disease genes, it was perplexing that neither L-type $\mathrm{Ca}^{2+}$ channel blockers nor $\mathrm{Na}^{+}$channel blockers prevented the paradoxical depolarization in low $\mathrm{K}^{+}(25)$. The first mechanistic insight was gleaned from the remarkable clustering of 6 of $7 \mathrm{Ca}_{v} 1.1$ mutations and all $8 \mathrm{Na}_{\mathrm{V}} 1.4$ mutations at arginine residues in S4 voltage sensor segments $(10,11,17)$. In response to changes in membrane potential, the $\alpha$-helical S4 segment translocates through a crevasse or gating pore in the channel protein (30) and thereby regulates opening of the central pore. Missense mutations in the S4 segments of $\mathrm{K}_{V}$ or $\mathrm{Na}_{\mathrm{V}}$ channels may permit leakage ion conduction, resulting in an anomalous gating pore current $(18,19,31)$. The leak is voltage dependent, since the access pathway is regulated by translocation of the S4 segment (Figure 6C). This anomalous inward current has been hypothesized to be the cause for depolarization of $V_{\text {rest }}$ during an attack of HypoPP. Indeed, all $6 \mathrm{Na}_{\mathrm{V}} 1.4$ HypoPP mutations examined by expression in oocytes have supported gating pore currents that conduct at the resting potential and are closed by depolarization $(16,17,21)$. 
A
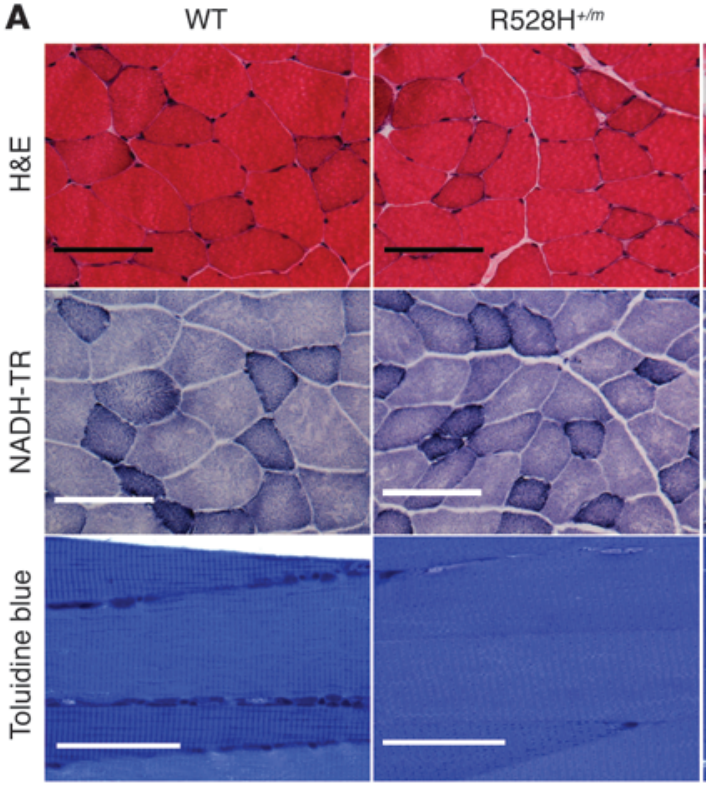

B
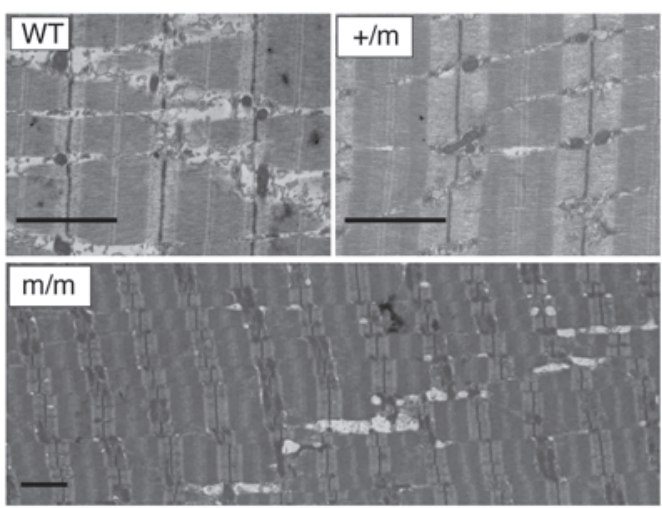

$\mathrm{R} 528 \mathrm{H}^{\mathrm{m} / m}$
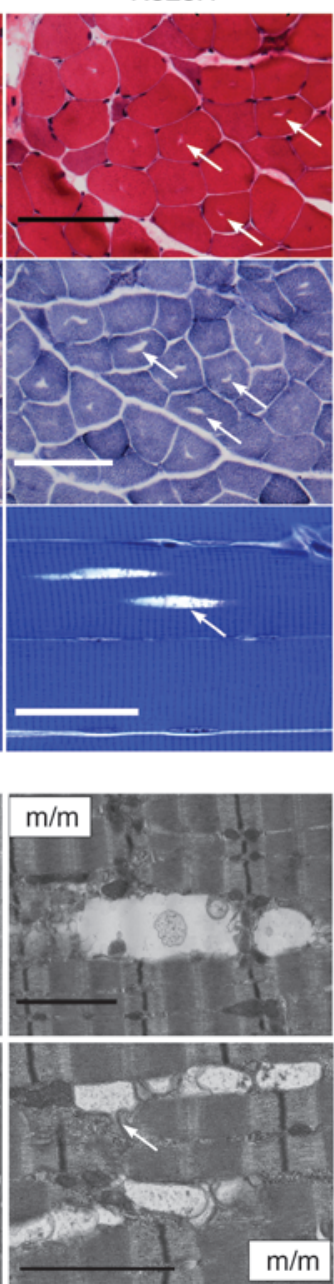

\section{Figure 9}

Vacuolar myopathy in gastrocnemius muscle from $\mathrm{R} 528 \mathrm{H}$ mice. (A) Transverse $10-\mu \mathrm{m}$ cryostat sections stained with $\mathrm{H} \& \mathrm{E}$ and NADH-TR demonstrated small, optically clear central vacuoles (arrows) in R528H $\mathrm{m} / \mathrm{m}$ fibers. Longitudinal $1.5-\mu \mathrm{m}$ sections of resin-embedded fibers stained with toluidine blue show the linear extent of the vacuoles. Vacuolar changes were not detected by light microscopy in WT or $\mathrm{R} 528 \mathrm{H}^{+/ m}$ fibers. Scale bars: $100 \mu \mathrm{m}$. (B) Ultrastructural studies from gastrocnemius muscle showed large, well-demarcated vacuoles with disruption of the triad junction in $\mathrm{R} 528 \mathrm{H} \mathrm{m} / \mathrm{m}$ fibers. Some vacuoles were continuous, with membrane-lined protuberances oriented transversely to the fiber axis (arrow, bottom right), suggesting that the vacuoles were dilated transverse tubules. Other sections showed large vacuoles at the normal position of the junctional SR, suggesting dilation of the sarcoplasmic reticulum as well. A lower-magnification EM image demonstrates that the vacuolar changes were extensive, with a substantial portion of sarcomeres being affected in $\mathrm{R} 528 \mathrm{H}^{\mathrm{m} / \mathrm{m}}$ muscle (bottom left). Rare, mildly dilated cisternae of the sarcoplasmic reticulum were observed in heterozygous $\mathrm{R}^{2} 28 \mathrm{H}^{+/ m}$ muscle, although no large vacuoles were observed of the type present in homozygous $\mathrm{R} 528 \mathrm{H}$ fibers. No ultrastructural abnormalities were present in the WT muscle. Scale bars: $2 \mu \mathrm{m}$.
Because $\mathrm{Ca}_{V} 1.1$ does not express well outside of muscle, it has not been possible to determine whether $\mathrm{R} 528 \mathrm{H}$ supports a gating pore current. Voltage clamp studies in HypoPP R528H fibers from human biopsies have detected an inward current at hyperpolarized potentials that does not occur in normal fibers $(24,25)$, but the source of this cation leak was not determined. Our voltage clamp measurements in homozygous $\mathrm{R} 528 \mathrm{H}^{\mathrm{m} / m}$ fibers revealed a voltagedependent inward current activated by hyperpolarization, blocked by $\mathrm{La}^{3+}$, and not blocked by tetrodotoxin (TTX), $\mathrm{Ba}^{2+}$, or 4-aminopyridine, consistent with a gating pore current homologous to those recorded from $\mathrm{Na}_{V} 1.4$ HypoPP mutants expressed in oocytes (23). The slope conductance for the gating pore current in mouse $\mathrm{R} 528 \mathrm{H}^{m / m}$ fibers was $28 \mu \mathrm{S} / \mathrm{cm}^{2}$, which is equivalent to $14 \mu \mathrm{S} / \mathrm{cm}^{2}$ in the heterozygous state and closely agrees with the $12 \mu \mathrm{S} / \mathrm{cm}^{2}$ cation leak observed in human $\mathrm{R} 528 \mathrm{H}$ fibers (24). The resting potential in muscle fibers is set from the balance of an outward $\mathrm{K}_{\mathrm{IR}}$ current and inward cation leak. The contribution from $\mathrm{K}_{\mathrm{IR}}$ diminishes as external $\mathrm{K}^{+}$is lowered, and computer simulations have shown that the additional inward current from an anomalous gating pore leak is sufficient to overwhelm $\mathrm{K}_{\mathrm{IR}}$ when $\mathrm{K}^{+}$falls below $3 \mathrm{mM}$. In this situation, the resting potential paradoxically depolarizes until the delayed rectifier $\mathrm{K}^{+}$conductance is activated and a new balance of inward and outward currents is achieved at about
$-60 \mathrm{mV}(11,23,24)$. Sodium channel inactivation is substantial at $-60 \mathrm{mV}$, and loss of force results from reduced excitability or even failure to generate propagated action potentials. Studies in human $\mathrm{R} 528 \mathrm{H}$ fibers $(25,32)$ and the chronically K-depleted rat model of HypoPP (33) have revealed a reduction in the density of the $K_{I R}$ current that is further exacerbated by insulin signaling. A loss of $\mathrm{K}_{\mathrm{IR}}$ current would synergistically aggravate the instability of the resting potential produced by a gating pore leakage current (23). It remains to be determined whether these changes in $\mathrm{K}_{\mathrm{IR}}$ occur in our $\mathrm{Ca}_{\mathrm{V}} 1.1 \mathrm{R} 528 \mathrm{H}$ mice. The demonstration of gating pore currents conducted by $\mathrm{Ca}_{V} 1.1 \mathrm{R} 528 \mathrm{H}$ and $\mathrm{Na}_{\mathrm{V}} 1.4$ HypoPP mutant channels provides a unifying explanation for how missense mutations in either of 2 cation channels with very different roles in skeletal muscle can both result in a common HypoPP phenotype.

In addition to the gating pore current, other defects in $\mathrm{R} 528 \mathrm{H}$ fibers may contribute to reduced contractility. The prominent vacuolar changes in homozygous $\mathrm{R} 528 \mathrm{H}^{m / m}$ fibers disrupted the triad junctions and severely impaired voltage-dependent $\mathrm{Ca}^{2+}$ release (Figure 8). While $\mathrm{Ca}^{2+}$ release was only mildly impaired in heterozygous $\mathrm{R} 528 \mathrm{H}^{+/ m}$ fibers, the cumulative reduction of myoplasmic $\mathrm{Ca}^{2+}$ during a train of discharges may be functionally significant. These changes may contribute to permanent weakness and aggravate the transient hypokalemic attacks. Prior studies using FURA-2 and less 
sensitive optical methods did not detect a defect in myoplasmic $\mathrm{Ca}^{2+}$ transients in human $\mathrm{R} 528 \mathrm{H}$ fibers or $m d g$ myotubes transfected with $\mathrm{Ca}_{V} 1.1 \mathrm{R} 528 \mathrm{H}$ (34). Loss-of-function changes were also observed for the ion-conducting properties of Cav1.1 R528H channels. In homozygous $\mathrm{R} 528 \mathrm{H}^{\mathrm{m} / m}$ fibers the current density was reduced to half that of WT fibers and activation kinetics were slowed (Figure 6). The relative decrease in ionic current density exceeded the reduction in expression level, as assessed by gating charge displacement, which suggests a partial uncoupling of voltage sensor motion to channel opening. Similar changes have previously been reported from studies using human $\mathrm{R} 528 \mathrm{H}$ myotubes (14) or heterologous expression in oocytes (35) or L cells (15). Since the R528H mutation lies in an $\mathrm{S} 4$ voltage sensor, the functional consequence was initially predicted to be a shift in the voltage dependence of gating. However, the voltage midpoint for activation, gating charge displacement, and $\mathrm{Ca}^{2+}$ release have consistently been reported to be unaffected by $\mathrm{R} 528 \mathrm{H}$ $(14,15,34,35)$, as observed herein.

\section{Methods}

Generation of CaV1.1 R528H knockin mice. A gene-targeting approach was used to introduce the homolog of the human HypoPP mutation Cav1.1 $\mathrm{R} 528 \mathrm{H}$ into exon 11 of the mouse CACNA1S (Figure 1). The targeting vector was constructed in pGKNeoLoxPDt2 (a gift from M. Tallquist, University of Texas Southwestern Medical Center), which contained the R528H codon (CGC $\rightarrow \mathrm{CAC}$ ), a transcriptionally silent EcoRV site to aid in genotyping by restriction digest, and 9.2-kb flanking genomic sequence. ES cells were electroporated with linearized vector, screened for diphtheria toxin resistance, and injected into blastocysts at the University of Texas Southwestern Transgenic Core Facility. After establishing germline transmission in F1 mice, the NeoR gene from the intron immediately $3^{\prime}$ to exon 11 was excised by breeding with a Cre recombinase-expressing strain. All animals used in this study had a 129/SV background. Mice aged 3-6 months were used for the physiological studies.

Genotyping and RNA expression. Genotyping was performed on tail-snip DNA using PCR amplification with intronic primers flanking exon 11 (forward, GACTTAGTGCCTTGGAAAGGTAGGGAGTGTACTGG; reverse, GACAAAAGGAGAAATAAGCATCGAGTGGAGTAAGTGG). Amplimers were resolved on a $1 \%$ agarose gel on which detection of the mutant allele was visualized as a larger band from the retained loxP site (580 bp compared with $500 \mathrm{bp}$ for WT) or by an EcoRV site.

Total RNA was isolated from gastrocnemius muscle using TRI Reagent BD (Sigma-Aldrich). First-strand cDNAs were synthesized using the SuperScript III system (Invitrogen). PCR amplification for 21 cycles was performed with allele-specific forward primers (R528 forward, GGCATCTCTGTGCTCCG; H528 forward, GGGATATCTGTGCTCCA) and a common reverse primer (AGCAGCAAGAGGGAAGCAAT) separated by approximately $9 \mathrm{~kb}$ of genomic sequence. The expected 128-bp amplimer from the cDNA template was resolved on a $3 \%$ agarose gel (NuSieve GTG; Cambrex Bio Science) and confirmed with sequencing. Relative expression levels were quantified by optical density measurement and compared with a control for template quality using a $\beta$-actin amplimer.

Histological studies. Mice were anesthetized with isoflurane inhalation and sacrificed by cervical dislocation. Segments from TA muscle and the gastrocnemius/soleus muscles were obtained from WT, $\mathrm{R} 528 \mathrm{H}^{+/ m}$, and $\mathrm{R} 528 \mathrm{H}^{m / m}$ mice. For light microscopic studies, muscle segments were snap-frozen in 2-methylbutane, cooled in liquid nitrogen, and sectioned at $10-\mu \mathrm{m}$ thickness on a Leitz rotary crytome at $-20^{\circ} \mathrm{C}$. Sequential sections were stained with $\mathrm{H} \& \mathrm{E}$ and using the $\mathrm{NADH}$-tetrazolium reductase procedure with standard methodologies (36). Muscle used in ultrastructural evaluations was fixed isometrically in $3 \%$ phosphate-buffered glutaraldehyde. Following fixation, longitudinally oriented segments of skeletal muscle measuring approximately $1 \mathrm{~mm}$ in diameter were washed in phosphate buffer, fixed for 1 hour in $1 \%$ osmium tetroxide, dehydrated in graded ethyl alcohol, and placed into propylene oxide for 10 minutes. Segments were taken through graded incubations of propylene oxide to pure resin and polymerized overnight at $65^{\circ} \mathrm{C}$. Following resin embedding, segments were sectioned in the longitudial plane at $1.5-\mu \mathrm{m}$ intervals on a Leica Ultracut ultramicrotome, stained with toluidine blue, and evaluated by light microscopy. For ultrastructural evaluation, resin blocks were sectioned in the transverse plane at $100-\mathrm{nm}$ intervals, stained sequentially with uranyl acetate and lead citrate, and examined with a Hitachi 7500 transmission electron microscope at $100 \mathrm{kV}$.

Long-term CMAP and force measurement in anesthetized mice. Mice were pretreated for 2-4 days with fudge plus sodium polystyrene sulfonate (Kayexalate; KVK-TECK Inc.) to reduce baseline extracellular $\mathrm{K}^{+}$. Potassium and glucose levels were measured from venous blood drawn before and after completion of the i.v. insulin plus glucose challenge, as previously described (22). The CMAP and force in the Achilles tendon in mice anesthetized by isoflurane inhalation were monitored every 2 minutes in response to electrical stimulation of the sciatic nerve, as previously described (22).

In vitro tetanic force measurement. Peak tetanic force was measured for the EDL muscle stimulated directly by parallel wires aligned perpendicular to the fiber axis, as previously described (22). Briefly, the EDL was rapidly dissected and mounted in an organ bath maintained at $37^{\circ} \mathrm{C}$ containing (in mM) $118 \mathrm{NaCl}, 4.75 \mathrm{KCl}, 1.18 \mathrm{MgSO}_{4}, 2.5 \mathrm{CaCl}_{2}, 1.18 \mathrm{NaH}_{2} \mathrm{PO}_{4}, 24.8$ $\mathrm{NaHCO}_{3}$, and 10 glucose, and $0.0220 \mathrm{mU} / \mathrm{ml}$ insulin containing $0.015 \mathrm{mg}$ $\mathrm{Zn}^{2+}$ per 100 units (Humulin R; Eli Lilly and Co.). D-tubocurarine (0.25 $\mu \mathrm{M}$; Sigma-Aldrich) was added to block fiber activation from motor nerve endings, and the bath was continuously bubbled with $95 \% \mathrm{O}_{2}$ and $5 \%$ $\mathrm{CO}_{2}$. Tetanic contractions were evoked by a train of 30 pulses of $1 \mathrm{~ms}$ in duration, $70 \mathrm{~mA}$ at $250 \mathrm{~Hz}$ (A385 Stimulator; WPI Inc.) delivered every 2 minutes. Test solutions were prewarmed to $37^{\circ} \mathrm{C}$ and were composed of varying concentrations of $\mathrm{KCl}(1,2,3,8$, and $10 \mathrm{mM})$ and $\mathrm{NaCl}(122,121$, 120,115 , and $113 \mathrm{mM}$ to maintain constant monovalent concentration.

Electrophysiological studies on individual fibers. $V_{\text {rest }}$ was measured in fibers from the soleus muscle mounted on an upright microscope stage. The bath composition was the same as that for the in vitro contraction studies and was maintained at $37^{\circ} \mathrm{C}$. $V_{\text {rest }}$ was recorded as the initial membrane potential measured upon fiber impalement with a $3-\mathrm{M} \mathrm{KCl}$ sharp microelectrode. Action potentials were measured from current clamp recordings performed with 2 microelectrodes controlled by an Axopatch 2B amplifier. Dantrolene $(3 \mu \mathrm{g} / \mathrm{ml})$ and the skeletal muscle myosin II inhibitor BTS $(20 \mu \mathrm{M})$ were added to suppress contractions.

Ionic currents, charge displacement current, and myoplasmic $\mathrm{Ca}^{2+}$ transients were recorded in single fibers enzymatically dissociated from the intrinsic muscles of hindfoot (flexor digitorum brevis and lumbricales muscles) (37). Currents were measured with a 2-electrode voltage clamp (Axopatch 2B), as previously described (37). The ionic current conducted by $\mathrm{Ca}_{V} 1.1$ channels was measured with $\mathrm{Ba}^{2+}$ as the charge carrier in a solution containing (in $\mathrm{mM}) 2 \mathrm{Ba}(\mathrm{OH})_{2}, 1 \mathrm{Mg}(\mathrm{OH})_{2}, 140$ TEAOH, 10 HEPES, and 10 glucose as well as methanesulfonic acid to set the $\mathrm{pH}$ to 7.4. Charge displacement current was measured by adding $1 \mathrm{mM} \mathrm{Co}(\mathrm{OH})_{2}$ and $0.1 \mathrm{mM}$ $\mathrm{La}(\mathrm{OH})_{3}$ to block ionic currents in $\mathrm{Ca}_{v} 1.1$ channels. Resting myoplasmic $\mathrm{Ca}^{2+}$ levels were measured in dissociated fibers loaded with the ratiometric dye Indo-1 AM, as previously described (38). Myoplasmic $\mathrm{Ca}^{2+}$ transients were measured using high-speed confocal imaging (LSM 5 LIVE; Zeiss) in fibers loaded with Fluo-4 AM (39). Brief electrical field stimuli were applied by 2 parallel platinum wires to elicit $\mathrm{Ca}^{2+}$ transients triggered by action potentials. Transients were also recorded from fibers voltage clamped in the whole cell patch mode, as previously described (40). 
Statistics. Data are presented as means \pm SEM. The 1-sided ANOVA at the $\alpha=0.05$ level was used to test for a significant difference of the means among the 3 genotypes. In cases where a difference in the means was present, the post-hoc Bonferroni correction was used to individually test whether $\mathrm{R} 528 \mathrm{H}^{+/ m}$ or $\mathrm{R} 528 \mathrm{H}^{m / m}$ differed from WT.

Study approval. All procedures were in accordance with animal protocols approved by the University of Texas Southwestern Medical Center Institutional Animal Care and Use Committee.

\section{Acknowledgments}

This work was supported by the Muscular Dystrophy Association (grant MDA 135815, to S.C. Cannon), by an ARRA Administrative Supplement to National Institute of Arthritis and Musculoskeletal and Skin Diseases (NIAMS) grant AR-42703 (to S.C. Cannon), and by NIAMS grants AR-063182 (to S.C. Cannon) and AR-055099 (to M.F. Schneider). The authors thank C. Franzini-Armstrong for assistance with interpretation of the EM studies.

Received for publication July 30, 2012, and accepted in revised form September 6, 2012.

Address correspondence to: Stephen C. Cannon, Department of Neurology and Neurotherapeutics, UT Southwestern Medical Center, 5323 Harry Hines Blvd., Dallas, Texas 75390-8813, USA. Phone: 214.633.1870; Fax: 214.648.6306; E-mail: Steve.cannon@ utsouthwestern.edu.
1. Cannon SC. Pathomechanisms in channelopathies of skeletal muscle and brain. Annu Rev Neurosci. 2006;29:387-415.

2. Lehmann-Horn F, Rüdel R, Jurkat-Rott K. Nondystrophic myotonias and periodic paralyses. In: Engel AG, Franzini-Armstrong, C, eds. Myology. 3rd ed. New York, New York, USA: McGraw-Hill. 2004:1257-1300.

3. Rüdel R, Lehmann-Horn F, Ricker K, Kuther G. Hypokalemic periodic paralysis: in vitro investigation of muscle fiber membrane parameters. Muscle Nerve. 1984;7(2):110-120.

4. Elbaz A, et al. Hypokalemic periodic paralysis and the dihydropyridine receptor (CACNL1A3): genotype/phenotype correlations for two predominant mutations and evidence for the absence of a founder effect in 16 caucasian families. Am J Hum Genet. 1995;56(2):374-380.

5. Links TP, Zwarts MJ, Wilmink JT, Molenaar WM, Oosterhuis HJ. Permanent muscle weakness in familial hypokalaemic periodic paralysis. Clinical, radiological and pathological aspects. Brain. 1990; 113(pt 6):1873-1889.

6. Sternberg D, et al. Hypokalaemic periodic paralysis type 2 caused by mutations at codon 672 in the muscle sodium channel gene SCN4A. Brain. 2001; 124(pt 6):1091-1099.

7. Ptacek LJ, et al. Dihydropyridine receptor mutations cause hypokalemic periodic paralysis. Cell. 1994;77(6):863-868.

8. Jurkat-Rott K, et al. A calcium channel mutation causing hypokalemic periodic paralysis. Hum Mol Genet. 1994;3(8):1415-1419.

9. Bulman DE, et al. A novel sodium channel mutation in a family with hypokalemic periodic paralysis. Neurology. 1999;53(9):1932-1936.

10. Matthews E, et al. Voltage sensor charge loss accounts for most cases of hypokalemic periodic paralysis. Neurology. 2009;72(18):1544-1547.

11. Cannon SC. Voltage-sensor mutations in channelopathies of skeletal muscle. J Physiol. 2010; 588(pt 11):1887-1895.

12. Struyk AF, Scoggan KA, Bulman DE, Cannon SC. The human skeletal muscle Na channel mutation $\mathrm{R} 669 \mathrm{H}$ associated with hypokalemic periodic paralysis enhances slow inactivation. J Neurosci. 2000; 20(23):8610-8617.

13. Jurkat-Rott K, et al. Voltage-sensor sodium channel mutations cause hypokalemic periodic paralysis type 2 by enhanced inactivation and reduced current. Proc Natl Acad Sci U S A. 2000;97(17):9549-9554.

14. Morrill JA, Brown RH Jr, Cannon SC. Gating of the L-type Ca channel in human skeletal myotubes: an activation defect caused by the hypokalemic periodic paralysis mutation R528H. J Neurosci. 1998;18(24):10320-10334.

15. Lapie P, Goudet C, Nargeot J, Fontaine B, Lory P. Electrophysiological properties of the hypokalaemic periodic paralysis mutation $(\mathrm{R} 528 \mathrm{H})$ of the skeletal muscle alpha 1s subunit as expressed in mouse L cells. FEBS Lett. 1996;382(3):244-248.

16. Struyk AF, Cannon SC. A Na ${ }^{+}$channel mutation linked to hypokalemic periodic paralysis exposes a proton-selective gating pore. J Gen Physiol. 2007; 130(1):11-20.

17. Sokolov S, Scheuer T, Catterall WA. Gating pore current in an inherited ion channelopathy. Nature. 2007;446(7131):76-78

18. Tombola F, Pathak MM, Isacoff EY. Voltage-sensing arginines in a potassium channel permeate and occlude cation-selective pores. Neuron. 2005; 45(3):379-388.

19. Starace DM, Stefani E, Bezanilla F. Voltage-dependent proton transport by the voltage sensor of the Shaker K+ channel. Neuron. 1997;19(6):1319-1327.

20. Struyk AF, Markin VS, Francis D, Cannon SC. Gating pore currents in DIIS4 mutations of NaV1.4 associated with periodic paralysis: saturation of ion flux and implications for disease pathogenesis. J Gen Physiol. 2008;132(4):447-464.

21. Francis DG, Rybalchenko V, Struyk A, Cannon SC. Leaky sodium channels from voltage sensor mutations in periodic paralysis, but not paramyotonia. Neurology. 2011;76(19):1635-1641.

22. Wu F, et al. A sodium channel knockin mutant (NaV1.4-R669H) mouse model of hypokalemic periodic paralysis. J Clin Invest. 2011;121(10):4082-4094.

23. Struyk AF, Cannon SC. Paradoxical depolarization of $\mathrm{Ba}^{2+}$ - treated muscle exposed to low extracellular $\mathrm{K}+$ : insights into resting potential abnormalities in hypokalemic paralysis. Muscle Nerve. 2008; 37(3):326-337.

24. Jurkat-Rott K, et al. K+-dependent paradoxical membrane depolarization and $\mathrm{Na}+$ overload, major and reversible contributors to weakness by ion channel leaks. Proc Natl Acad Sci U S A. 2009; 106(10):4036-4041.

25. Ruff RL. Insulin acts in hypokalemic periodic paralysis by reducing inward rectifier $\mathrm{K}+$ current. Neurology. 1999;53(7):1556-1563.

26. Rios E, Brum G. Involvement of dihydropyridine receptors in excitation-contraction coupling in skeletal muscle. Nature. 1987;325(6106):717-720.

27. Tanabe T, Beam KG, Powell JA, Numa S. Restoration of excitation-contraction coupling and slow calcium current in dysgenic muscle by dihydropyridine receptor complementary DNA. Nature. 1988; 336(6195):134-139.
28. Lynch PJ, et al. A mutation in the transmembrane/ luminal domain of the ryanodine receptor is associated with abnormal $\mathrm{Ca} 2+$ release channel function and severe central core disease. Proc Natl Acad SciUS A. 1999;96(7):4164-4169.

29. Dirksen RT, Avila G. Distinct effects on Ca2+ handling caused by malignant hyperthermia and central core disease mutations in RyR1. Biophys J. 2004;87(5):3193-3204.

30. Yang N, George AL Jr, Horn R. Molecular basis of charge movement in voltage-gated sodium channels. Neuron. 1996;16(1):113-122.

31. Sokolov S, Scheuer T, Catterall WA. Ion permeation through a voltage- sensitive gating pore in brain sodium channels having voltage sensor mutations. Neuron. 2005;47(2):183-189.

32. Tricarico D, Servidei S, Tonali P, Jurkat-Rott K, Camerino DC. Impairment of skeletal muscle adenosine triphosphate-sensitive $\mathrm{K}+$ channels in patients with hypokalemic periodic paralysis. J Clin Invest. 1999;103(5):675-682.

33. Bond EF, Gordon AM. Insulin-induced membrane changes in $\mathrm{K}(+)$-depleted rat skeletal muscle. Am J Physiol. 1993;265(1 pt 1):C257-C265.

34. Jurkat-Rott K, et al. Calcium currents and transients of native and heterologously expressed mutant skeletal muscle DHP receptor alpha1 subunits (R528H). FEBS Lett. 1998;423(2):198-204.

35. Morrill JA, Cannon SC. Effects of mutations causing hypokalaemic periodic paralysis on the skeletal muscle L-type Ca2+ channel expressed in xenopus laevis oocytes. J Physiol (Lond). 1999;520(pt 2):321-336.

36. De Paepe B, De Bleecker JL, Van Coster R. Histochemical methods for the diagnosis of mitochondrial diseases. Curr Protoc Hum Genet Chapter. 2009; 19:Unit19.12.

37. Fu Y, Struyk A, Markin V, Cannon S. Gating behaviour of sodium currents in adult mouse muscle recorded with an improved two-electrode voltage clamp. J Physiol. 2011;589(pt 3):525-546.

38. Prosser BL, et al. S100A1 binds to the calmodulinbinding site of ryanodine receptor and modulates skeletal muscle excitation-contraction coupling. J Biol Chem. 2008;283(8):5046-5057.

39. Prosser BL, Hernandez-Ochoa EO, Zimmer DB, Schneider MF. Simultaneous recording of intramembrane charge movement components and calcium release in wild-type and S100A1-/- muscle fibres. J Physiol. 2009;587(pt 18):4543-4559.

40. Olojo RO, Hernandez-Ochoa EO, Ikemoto N, Schneider MF. Effects of conformational peptide probe DP4 on bidirectional signaling between DHPR and RyR1 calcium channels in voltage-clamped skeletal muscle fibers. BiophysJ. 2011;100(10):2367-2377. 